\title{
Clinical significance and therapeutic value of glutathione peroxidase 3 (GPX3) in hepatocellular carcinoma
}

\author{
Xiang $\mathbf{Q i}^{1}$, Kevin Tak Pan $\mathrm{Ng}^{1}$, Qi Zhou Lian ${ }^{2}$, Xiao Bing Liu ${ }^{1}$, Chang Xian $\mathrm{Li}^{1}$, \\ Wei Geng ${ }^{1}$, Chang Chun Ling ${ }^{1}$, Yuen Yuen Ma ${ }^{1}$, Wai Ho Yeung ${ }^{1}$, Wen Wei $\mathrm{Tu}^{3}$, \\ Sheung Tat Fan ${ }^{1}$, Chung Mau Lo', Kwan Man ${ }^{1}$

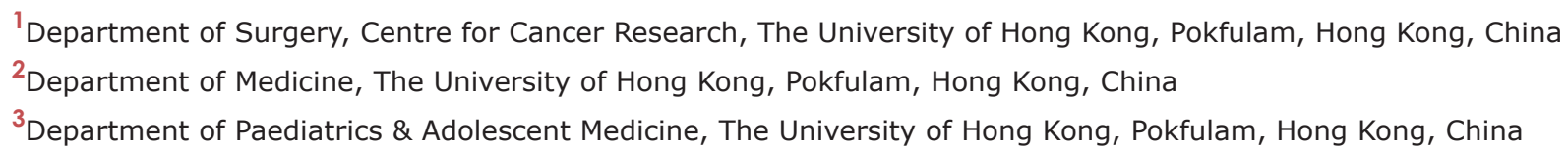

Correspondence to:

Kwan Man, e-mail: kwanman@hku.hk

Keywords: GPx3, HCC, hiPSC-MSCs, Tumor suppressor gene, Prognosis

Received: July 24, $2014 \quad$ Accepted: September 30, 2014

Published: October 11, 2014

\section{ABSTRACT}

Aims: We aimed to investigate the clinical significance of GPX3 in hepatocellular carcinoma (HCC) and to characterize its tumor suppressive role.

Methods: HCC patients (113) who underwent hepatectomy were recruited to examine the clinical relevance of GPX3. The tumor suppressive role of GPx3 was studied by administration of recombinant GPX3 (rGPX3) or over-expression of GPx3 in HCC cells in vitro and in vivo. The therapeutic value of GPX3 for HCC was further investigated using human induced pluripotent stem cell derived mesenchymal stem cells (hiPSC-MSCs) as its delivery vehicle.

Results: Down-regulation of GPx3 significantly correlated with advanced tumor stage $(P=0.024)$, venous infiltration $(P=0.043)$ and poor overall survival $(P=0.007)$ after hepatectomy. Lower plasma GPx3 in HCC patients was significantly associated with larger tumor size $(P=0.011)$, more tumor nodules $(P=0.032)$ and higher recurrence $(P=0.016)$. Over-expression of GPx3 or administration of rGPx3 significantly inhibited proliferation and invasiveness of $\mathrm{HCC}$ cells in vitro and in vivo. Tumor suppressive activity of GPx3 was mediated through Erk-NFKB-SIP1 pathway. GPX3 could be delivered by hiPSC-MSCs into the tumor and exhibited tumor suppressive activity in vivo.

Conclusions: GPx3 is a tumor suppressor gene in HCC and may possess prognostic and therapeutic value for HCC patients.

\section{INTRODUCTION}

Oxidative stress is fatal to normal cells. In contrast, it plays a key role in cell survival and proliferation of several types of cancer [1]. Unlimited proliferation of cancer cells, to some extent, relies on intracellular oxidants such as reactive oxygen species (ROS). Oxidative stress could cause genetic mutation [2], up-regulate signaling pathways that control cell survival and invasiveness [3] and provide favorable micro-environment for cancer development [4]. Therefore, attenuation of oxidative stress post-operation or combined with chemotherapy may provide new insights for cancer treatment.
Glutathione peroxidase 3 (GPx3) was found to be up-regulated in acute phase injury as an anti-oxidant to protect the organ from oxidative stress by detoxifying hydrogen peroxide and other free radicals $[5,6]$. It has also been noticed that expression of GPx 3 is significantly downregulated within tumor tissues in several types of cancers. The mRNA level of GPx3 is down-regulated in esophageal squamous cell carcinoma due to epigenetic silence [7]. The down-regulation of GPx3 was also observed in Barrett's adenocarcinoma because of DNA methylation [8]. Much lower expression levels of GPx3 were observed in colorectal cancer compared with non-tumor tissues [9]. Besides the down-regulation of GPx3 within tumor tissues, 
the circulating GPx3 was also found to be much lower in the patients with glioblastoma than non-patients which implies that it may possess the prognostic value for cancer patients [10]. Although the down-regulation of GPx3 was shown in several malignancies, the clinical significance and functional role of GPx3 in cancer development have not been well illustrated.

Hepatocellular carcinoma (HCC) is the sixth most common cancer and ranks as high as third for cancerrelated deaths worldwide [11]. Although tumor resection and liver transplantation are effective treatments for selected HCC patients, tumor recurrence remains a main concern [12-14]. Furthermore, surgical treatment is not applicable for patients with advanced tumor stages [15-18]. Development of a new approach to prevent tumor recurrence and improve prognosis is an urgent need for HCC patients. The role of anti-oxidant in treatment of HCC patients has not been illustrated. So far, there is no information about the role of GPx3 in HCC. Exploration of functional role of GPx 3 in HCC could provide new evidences to apply anti-oxidant agents for cancer therapy.

Firstly, we examined the clinical significance of GPx3 in HCC patients and found that lower expression of GPx3 in tumors could predict the advanced tumor stage and higher probability of tumor recurrence. Secondly, we explored the tumor suppressive activity of GPx3 in vitro by administration of rGPx3 or forced expression of GPx3 in different liver cancer cell lines. Thirdly, we demonstrated the anti-tumor effect of GPx3 in vivo using ectopic and orthotopic liver cancer models. Fourthly, we found that the tumor suppressive activity of GPx3 was mediated by inhibition of EMT (Epithelial-Mesenchymal Transition) through Erk-NFкB-SIP1 signaling pathway. Finally, we explored the therapeutic value of GPx3 for $\mathrm{HCC}$ using hiPSC-MSCs as a delivery vehicle. This is the first study to suggest the prognostic and therapeutic value of GPx3 in HCC patients.

\section{RESULTS}

\section{Expression of GPx3 was down-regulated within tumor tissues in HCC patients}

The average mRNA level of GPx3 was significantly lower within tumor tissues compared with adjacent nontumor tissues and normal liver tissues (Fig. 1A, left panel). The down-regulation of GPx3 in tumor tissues compared with adjacent non-tumor tissues was observed in $50 \%$ of HCC patients $(56 / 113)$. It seemed that the difference between normal and diseased samples were larger than that between tumor and non-tumor tissues (Fig. 1A, left panel). There are two possible explanations. On one hand, HCC is regarded as inflammation associated cancer, which always develops with the background of cirrhosis. In such types of cancer, the chronic inflammation is always inevitable and would cause the lower level of GPx3 expression.
On the other hand, the adjacent non-tumor tissue could be generally perceived as "pre-cancer" disease. Our results showed that GPx3 was already significantly down-regulated in such "pre-cancer" tissues. It implied that down-regulation of GPx3 may not only be involved in tumor progression, but also tumor development or carcinogenesis. Consistent with mRNA levels, the protein levels of GPx3 were also found down-regulated in tumor tissues (Fig. 1B). IHC staining also confirmed that lower expression of GPx3 was detected within tumor tissues (Fig. 1C).

\section{Down-regulation of GPx3 mRNA significantly correlated with advanced tumor stage and poor prognosis in HCC patients}

The association of GPx3 mRNA with clinicopathological parameters was analyzed (Table 1). Down-regulation of GPx3 was significantly correlated with advanced pTNM stage $(P=0.024)$, presence of venous infiltration $(P=0.043)$ and high AFP level $(P=0.006)$. The five year recurrence $(P=0.019)$ was significantly higher in the patients with GPx3 downregulation. No significant association of GPx3 expression was detected with sex, age, tumor size, number of tumor nodules and presence of hepatitis B surface antigen.

Kaplan-Meier survival analysis showed that the down-regulation of GPx3 mRNA was significantly correlated with poor overall survival of HCC patients (Log rank $=7.297, P=0.007$, Fig. 1A, right panel). The estimated mean overall survival time of the patients with GPx3 down-regulation was 58.72 \pm 6.94 months, which was significantly lower than that of patients without GPx3 down-regulation $(86.46 \pm 6.85$ months $)$. The independent predictor for overall survival was further identified among GPx3, pTNM stage, venous infiltration and AFP using Cox proportional hazard regression analysis (Table S1). In univariable analysis, down-regulation of GPx3 (HR=2.084, 95\%CI: 1.209-3.593, $P=0.008)$ was significantly associated with overall survival. However, in multivariable analysis, only venous infiltration (HR=3.003, 95\%CI: 1.259-7.160, $P=0.013$ ) was identified as an independent predictor.

\section{Lower plasma GPx3 significantly correlated with tumor progression and tumor recurrence in HCC patients}

The area under the ROC curve of plasma GPx3 was $0.643(0.534-0.751)$ for prediction of five year recurrence. The value $(4.842 \mu \mathrm{g} / \mathrm{mL})$ with a maximized Youden index was selected as the cutoff point by which all the patients were segregated into two groups: low and high level group. The larger tumor size $(P=0.011)$ and higher number of tumor nodules $(P=0.032)$ were found in the GPx3 low level group. The five year recurrence rate 
A

Fold change of GPx3 mRNA (2-AACt)
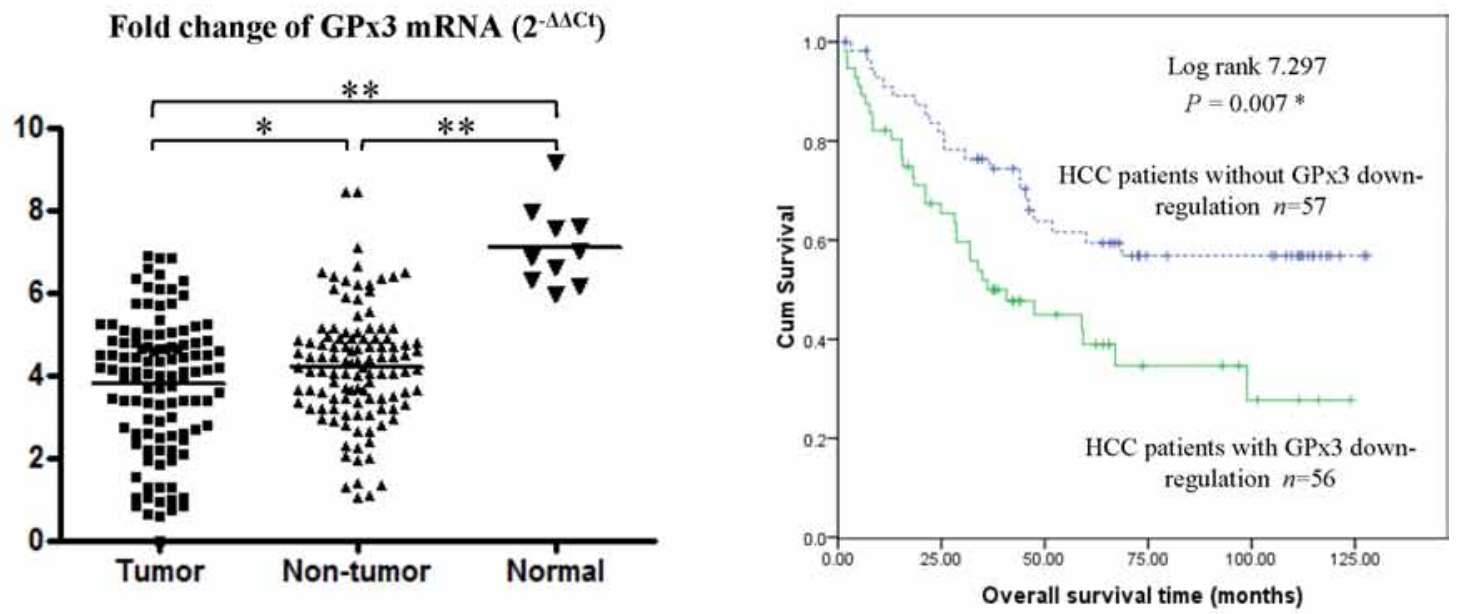

B

$$
\frac{\mathrm{P} 398}{\mathrm{~T} N \mathrm{NT}} \frac{\mathrm{P} 325}{\mathrm{~T} \quad \mathrm{NT}} \frac{\mathrm{P} 343}{\mathrm{~T} N \mathrm{NT}} \frac{\mathrm{P} 277}{\mathrm{~T} \text { NT }} \frac{\mathrm{P} 244}{\mathrm{~T} N \mathrm{NT}} \frac{\mathrm{P} 296}{\mathrm{~T} \text { NT }}
$$

GPx3

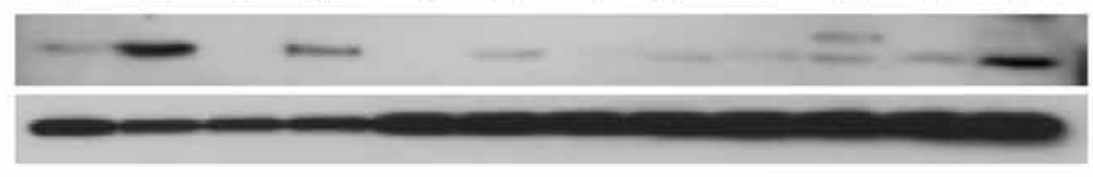

$\beta$-Actin

$$
\frac{\mathrm{P} 218}{\mathrm{~T} N \mathrm{NT}} \frac{\mathrm{P} 242}{\mathrm{~T} \text { NT }} \frac{\mathrm{P} 159}{\mathrm{~T} N \mathrm{NT}} \frac{\mathrm{P} 088}{\mathrm{~T} \quad \mathrm{NT}} \frac{\mathrm{P} 361}{\mathrm{~T} \text { NT }} \frac{\mathrm{P} 384}{\mathrm{~T} \text { NT }}
$$

GPx3

$\beta$-Actin

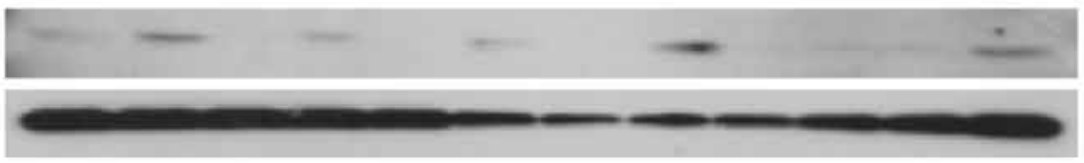

C

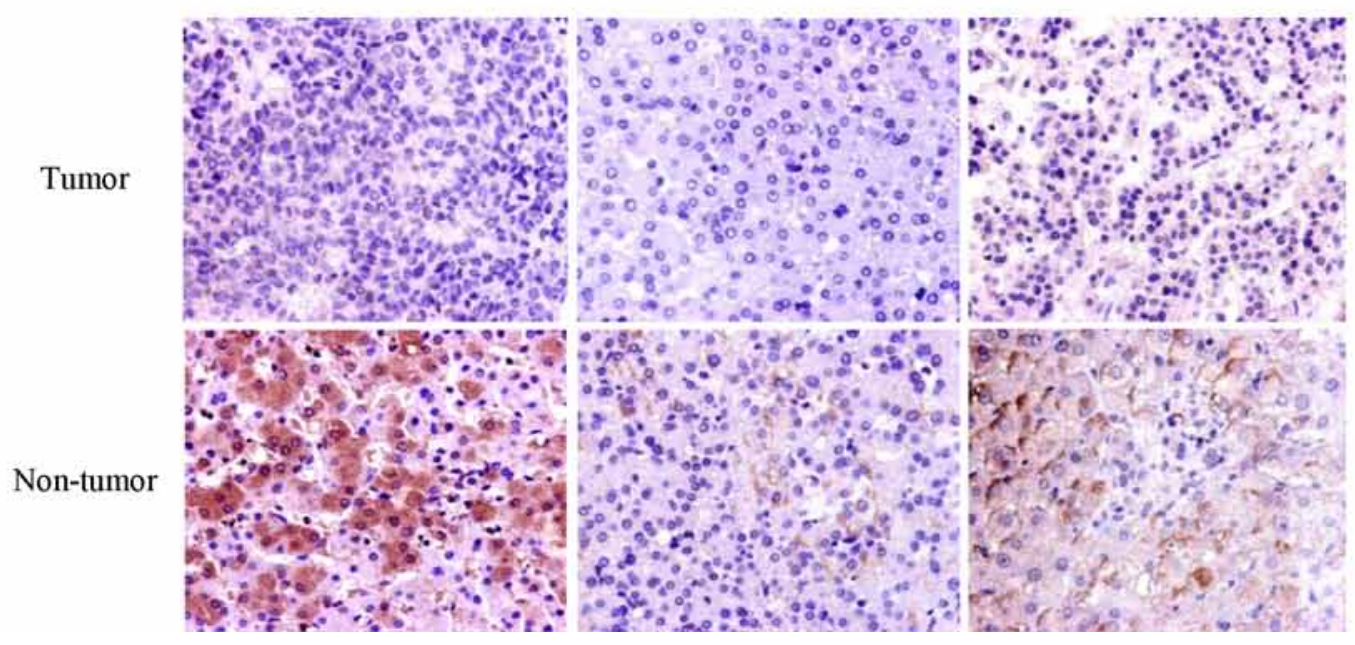

Figure 1: Down-regulation of GPx3 in HCC patients. (A) GPx3 mRNA in clinical samples (Left panel), ${ }^{*} P<0.05, * * P<0.01$. Overall survival of HCC patients underwent hepatectomy (Right penal), ${ }^{*} P<0.05$. (B) Representative images of down-regulation of GPx3 in tumor tissues compared with adjacent non-tumor tissues by Western-Blot. (C) Representative images of HE staining showing the downregulation of GPx3 within tumor tissue $(400 \times)$. 
Table 1: The correlation of GPx3 expression with clinical parameters of HCC patients

\begin{tabular}{|c|c|c|c|c|}
\hline \multirow[b]{2}{*}{ Clinicopathological features } & \multicolumn{4}{|c|}{ GPx3 expression level (n) } \\
\hline & Number & Down regulated & $\begin{array}{l}\text { Non-down } \\
\text { regulated }\end{array}$ & $P$ \\
\hline \multicolumn{4}{|l|}{ Sex } & \multirow{3}{*}{0.210} \\
\hline Male & 92 & 43 & 49 & \\
\hline Female & 21 & 13 & 8 & \\
\hline \multicolumn{4}{|l|}{ Age } & \multirow{3}{*}{0.926} \\
\hline Younger than 55 & 57 & 28 & 29 & \\
\hline Older than 55 & 56 & 28 & 28 & \\
\hline \multicolumn{4}{|l|}{ pTNM stage $^{a}$} & \multirow{3}{*}{$0.024 *$} \\
\hline Early stage (1-2) & 29 & 9 & 20 & \\
\hline Advanced stage (3-4) & 83 & 46 & 37 & \\
\hline \multicolumn{4}{|l|}{ Venous infiltration } & \multirow{3}{*}{$0.043 *$} \\
\hline Absent & 47 & 18 & 29 & \\
\hline Present & 66 & 38 & 28 & \\
\hline \multicolumn{4}{|l|}{ Tumor size $^{a}$} & \multirow{3}{*}{0.462} \\
\hline Less than $5 \mathrm{~cm}$ & 47 & 25 & 22 & \\
\hline More than $5 \mathrm{~cm}$ & 65 & 30 & 35 & \\
\hline \multicolumn{4}{|l|}{ Tumor Nodules $^{\mathrm{a}}$} & \multirow{3}{*}{0.448} \\
\hline Less than 3 & 83 & 39 & 44 & \\
\hline More than 3 & 29 & 16 & 13 & \\
\hline \multicolumn{4}{|l|}{ HBsAg } & \multirow{3}{*}{0.794} \\
\hline Negative & 13 & 6 & 7 & \\
\hline Positive & 100 & 50 & 50 & \\
\hline \multicolumn{4}{|l|}{ AFP level $^{a}$} & \multirow{3}{*}{$0.006^{*}$} \\
\hline Lower than $20 \mathrm{ng} / \mathrm{mL}$ & 45 & 15 & 30 & \\
\hline Higher than $20 \mathrm{ng} / \mathrm{mL}$ & 67 & 40 & 27 & \\
\hline \multicolumn{4}{|l|}{ One year recurrence ${ }^{a}$} & \multirow{3}{*}{$0.038 *$} \\
\hline Recurrence & 42 & 27 & 15 & \\
\hline Non-recurrence & 62 & 27 & 35 & \\
\hline \multicolumn{4}{|l|}{ Five year recurrence ${ }^{\mathrm{a}}$} & \multirow{3}{*}{$0.019 *$} \\
\hline Recurrence & 62 & 36 & 26 & \\
\hline Non-recurrence & 43 & 15 & 28 & \\
\hline
\end{tabular}

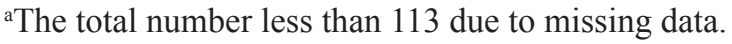

"Significant difference.

$(P=0.016)$ was significantly higher in the patients with low plasma GPx3 (Table 2). No significant association of plasma GPx3 was detected with age, sex, pTNM stage, venous infiltration and hepatitis B surface antigen. The patients with low plasma GPx3 had relatively shorter disease-free survival period (35.37 \pm 6.22 vs $49.14 \pm 7.11$ months). However, the difference did not reach statistical significance (Log rank=2.044, $P=0.153$ ). 
Table 2: The correlation of plasma GPx3 with clinical parameters of HCC patients

\begin{tabular}{|c|c|c|c|c|}
\hline \multirow{2}{*}{ Clinicopathological features } & \multicolumn{3}{|c|}{ Plasma GPx3 level (n) } & \multirow{2}{*}{$P$} \\
\hline & Number & Low level ${ }^{b}$ & High level $^{\mathrm{b}}$ & \\
\hline \multicolumn{4}{|l|}{ Sex } & \multirow{3}{*}{0.835} \\
\hline Male & 88 & 44 & 44 & \\
\hline Female & 19 & 9 & 10 & \\
\hline \multicolumn{4}{|l|}{ Age } & \multirow{3}{*}{0.210} \\
\hline Younger than 55 & 52 & 29 & 23 & \\
\hline Older than 55 & 55 & 24 & 31 & \\
\hline \multicolumn{4}{|l|}{ pTNM stage $^{a}$} & \multirow{3}{*}{0.353} \\
\hline Early stage (1-2) & 24 & 10 & 14 & \\
\hline Advanced stage (3-4) & 82 & 43 & 39 & \\
\hline \multicolumn{4}{|l|}{ Venous infiltration } & \multirow{3}{*}{0.750} \\
\hline Absent & 42 & 20 & 22 & \\
\hline Present & 65 & 33 & 32 & \\
\hline \multicolumn{4}{|l|}{ Tumor size $^{\mathrm{a}}$} & \multirow{3}{*}{$0.011 *$} \\
\hline Less than $5 \mathrm{~cm}$ & 45 & 16 & 29 & \\
\hline More than $5 \mathrm{~cm}$ & 61 & 37 & 24 & \\
\hline \multicolumn{4}{|l|}{ Tumor Nodules $^{\mathrm{a}}$} & \multirow{3}{*}{$0.032 *$} \\
\hline Less than 3 & 77 & 34 & 43 & \\
\hline More than 3 & 28 & 19 & 9 & \\
\hline \multicolumn{4}{|l|}{ HBsAg } & \multirow{3}{*}{0.518} \\
\hline Negative & 12 & 7 & 5 & \\
\hline Positive & 95 & 46 & 49 & \\
\hline \multicolumn{4}{|l|}{ AFP level $^{a}$} & \multirow{3}{*}{0.691} \\
\hline Lower than $20 \mathrm{ng} / \mathrm{mL}$ & 42 & 22 & 20 & \\
\hline Higher than $20 \mathrm{ng} / \mathrm{mL}$ & 64 & 31 & 33 & \\
\hline \multicolumn{4}{|l|}{ One year recurrence ${ }^{a}$} & \multirow{3}{*}{0.227} \\
\hline Recurrence & 42 & 24 & 18 & \\
\hline Non-recurrence & 60 & 27 & 33 & \\
\hline \multicolumn{4}{|l|}{ Five year recurrence ${ }^{\mathrm{a}}$} & \multirow{3}{*}{$0.016^{*}$} \\
\hline Recurrence & 61 & 36 & 25 & \\
\hline Non-recurrence & 38 & 13 & 25 & \\
\hline
\end{tabular}

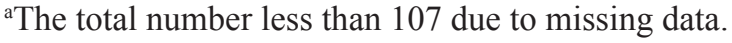

${ }^{b}$ The cutoff point with maximized Youden index was $4.842 \mu \mathrm{g} / \mathrm{mL}$ by which all the patients were segregated into two groups.

"Significant difference.

\section{Expression level of GPx3 in normal and HCC cell lines}

The mRNA level of GPx3 was significantly lower in HCC cell lines (except HepG2) compared with immortalized liver cell lines (MIHA and $\mathrm{LO}_{2}$ ) (Fig. 2A). Among HCC cell lines, the expression of GPx3 was significantly lower in metastatic HCC cell line (MHCC97L) compared with non-metastatic HCC cell lines (Hep3B and Huh7). 


\section{Recombinant GPx3 protein (rGPx3) or over-expression of GPx3 inhibited proliferation and invasiveness of $\mathrm{HCC}$ cells in vitro}

Administration of $\mathrm{rGPx} 3$ inhibited the proliferation of MHCC97L, Hep3B and Huh7, whose GPx3 was relatively low (Fig. 2B). The proliferation of HCC cells was most significantly suppressed by rGPx3 at the concentration of $2 \mu \mathrm{g} / \mathrm{mL}$, which was shown to be non-toxic to normal liver cells (MIHA) (Fig. 2B). The invasiveness of MHCC97L, Hep3B and Huh7 was also suppressed by administration of rGPx3 (Fig. 2C). The number of migrated cells was significantly lower upon rGPx3 administration in the Matrigel invasion assay (Fig. 2D).

Over-expression of GPx3 was established in Huh7 and MHCC97L. The clones with the highest expression of GPx3 were picked up for further investigation (Fig. S1A and B). We also confirmed that secreted GPx 3 was significantly increased in the culture medium after transfection (Fig. 3A). It implied that the forcedly expressed GPx 3 could be successfully secreted extracellularly. Over-expression of GPx3 significantly inhibited the proliferation (Fig. 3B) of Huh7 and MHCC97L in MTT assay. Moreover, in colony formation assay, the colony number and size were both significantly lower in GPx3 over-expression group (Fig. 3C). Furthermore, the invasiveness was also significantly suppressed by over-expression of GPx3 in Huh7 and MHCC97L (Fig. 3D).

\section{Over-expression of GPx3 suppressed tumor growth and invasiveness in vivo}

In nude mice ectopic liver cancer model, the tumor growth rate of MHCC97L-GPx3-2 was significantly lower compared with vector control (Fig. 4A and B). In nude mice orthotopic liver cancer model, tumor volume was significantly lower in MHCC97L-GPx3-2 group (Fig. 4C). The over-expression of GPx3 in MHCC97L-GPx3-2 group was also confirmed 5 weeks after tumor implantation (Fig. 4D). It implied that forced-expression of GPx3 could be sustained in vivo and secreted extracellularly. A relatively clear margin between tumor and adjacent non-tumor tissues was found in the MHCC97L-GPx3-2 group. On the contrary, invasive patterns of tumor growth were present in vector control group (Fig. 4E). The results showed that overexpression of GPx3 suppressed tumor invasiveness in vivo.

\section{GPx3 inhibited Epithelial-Mesenchymal Transition (EMT) through suppression of Smad Interacting Protein 1 (SIP1)}

As significant anti-invasiveness effect of GPx3 was observed in vitro and in vivo (Fig. 2C, 3D and 4E), we further investigated the effect of GPx3 on EMT process. GPx3 significantly inhibited EMT which was stimulated by TGF- $\beta$ in MHCC97L (Fig. 5A). GPx3 restored the expression of E-cadherin (epithelial marker) and decreased expression of Vimentin (mesenchymal marker) of MHCC97L.

In order to further investigate the underlying mechanism of inhibitory effect of GPx3 on EMT, several transcriptional repressors of E-cadherin that are commonly involved in EMT process, such as Slug, Snail, Zeb1, SIP1 and Twist, were selected for detection. In our case, SIP1 was shown to be most significantly suppressed by GPx3 treatment independent of TGF- $\beta$ stimulation (Fig. 5B).

\section{GPx3 suppressed SIP1 expression through inhibition of Nuclear Factor кB (NFкB) activation}

$\mathrm{NF} \kappa \mathrm{B}$ was reported to be directly involved in EMT process and is the key mediator for SIP1 expression [19]. In our study, SIP1 expression could be regulated by NFאB pathway as administration of specific NFKB inhibitor (PDTC) suppressed SIP1 expression (Fig. 5C, left panel). Furthermore, NFKB nuclear translocation was significantly attenuated upon $\mathrm{rGPx} 3$ administration, indicating that activation of $\mathrm{NF \kappa B}$ could be inhibited by GPx 3 treatment (Fig. 5C, right panel). Thus, GPx3 treatment might inhibit NFאB activation, which would further suppress SIP1 expression.

\section{GPx3 inhibited NFкB activation through deactivation of Extracellular signal-regulated kinase (Erk)}

PI3K-AKT and Ras-MEK-Erk signaling pathways are both commonly involved in liver cancer progression and are reported to be the activators of the NFkB signaling pathway [20,21]. In our case, the activated form of AKT remained unchanged upon rGPx3 administration (Fig. S2A). However, significant inhibition of Erk activation was observed upon rGPx3 administration (Fig. 5D, left panel). Furthermore, activation of NFkB could be regulated by the Erk pathway as evidenced by how the administration of specific Erk inhibitor (U0126) deactivated NFкB-p65 (Fig. 5D, right panel). Thus, GPx3 might inhibit Erk activation, which would further deactivate NFKB signaling pathway. The same trend could also be observed in orthotopic liver cancer model that activation of NFkB was inhibited by the over-expression of GPx3 through deactivation of Erk (Fig. 5E).

\section{GPx3 deactivated Erk by up-regulation of MAP Kinase Phosphatase 3 (MKP3)}

We further observed that the activation of Erk could be inhibited by GPx3 in a dose dependent manner (Fig. 5F, left panel). However, the up-stream stimulators of the 
A

Fold change of GPx3 mRNA (2-ACt)

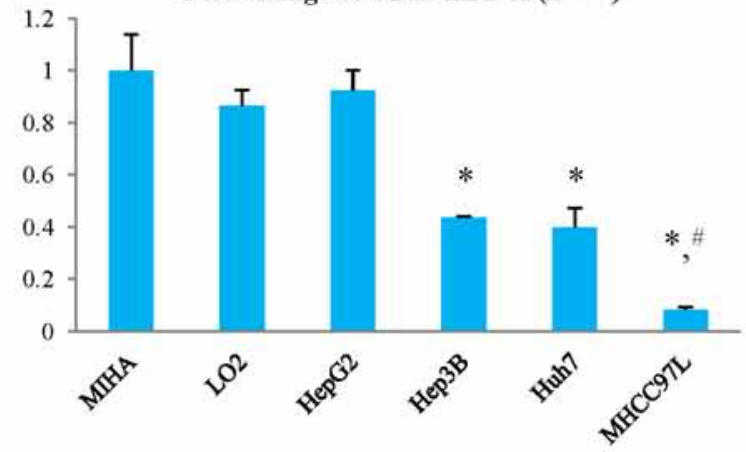

B
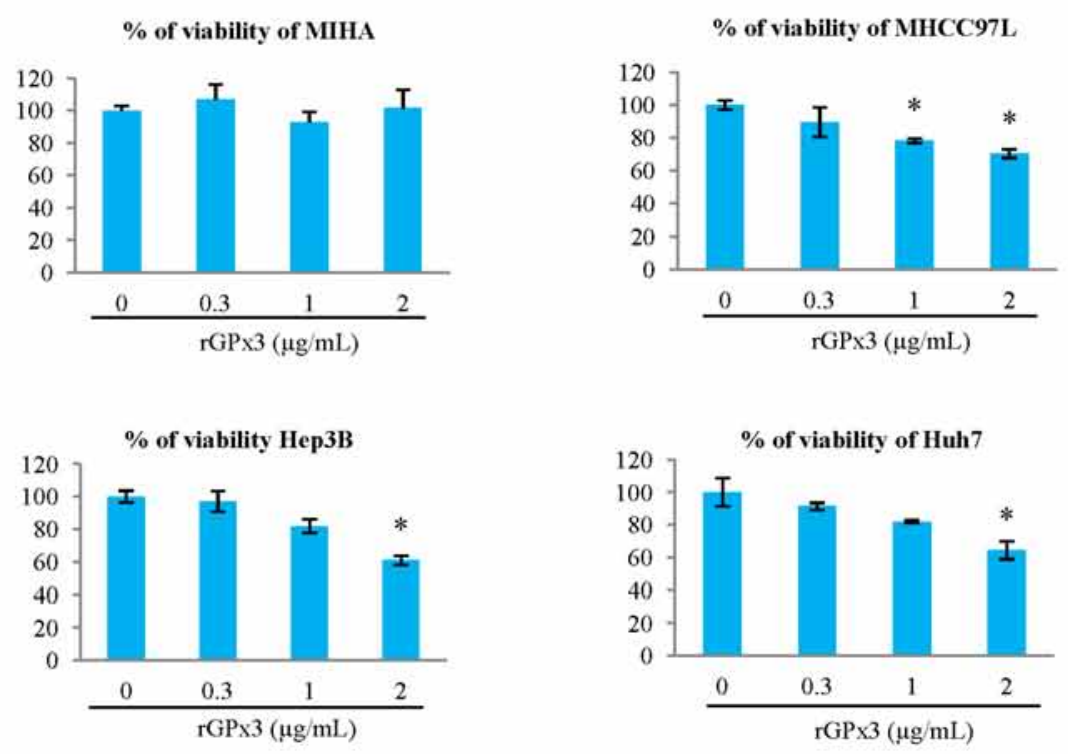

C

D
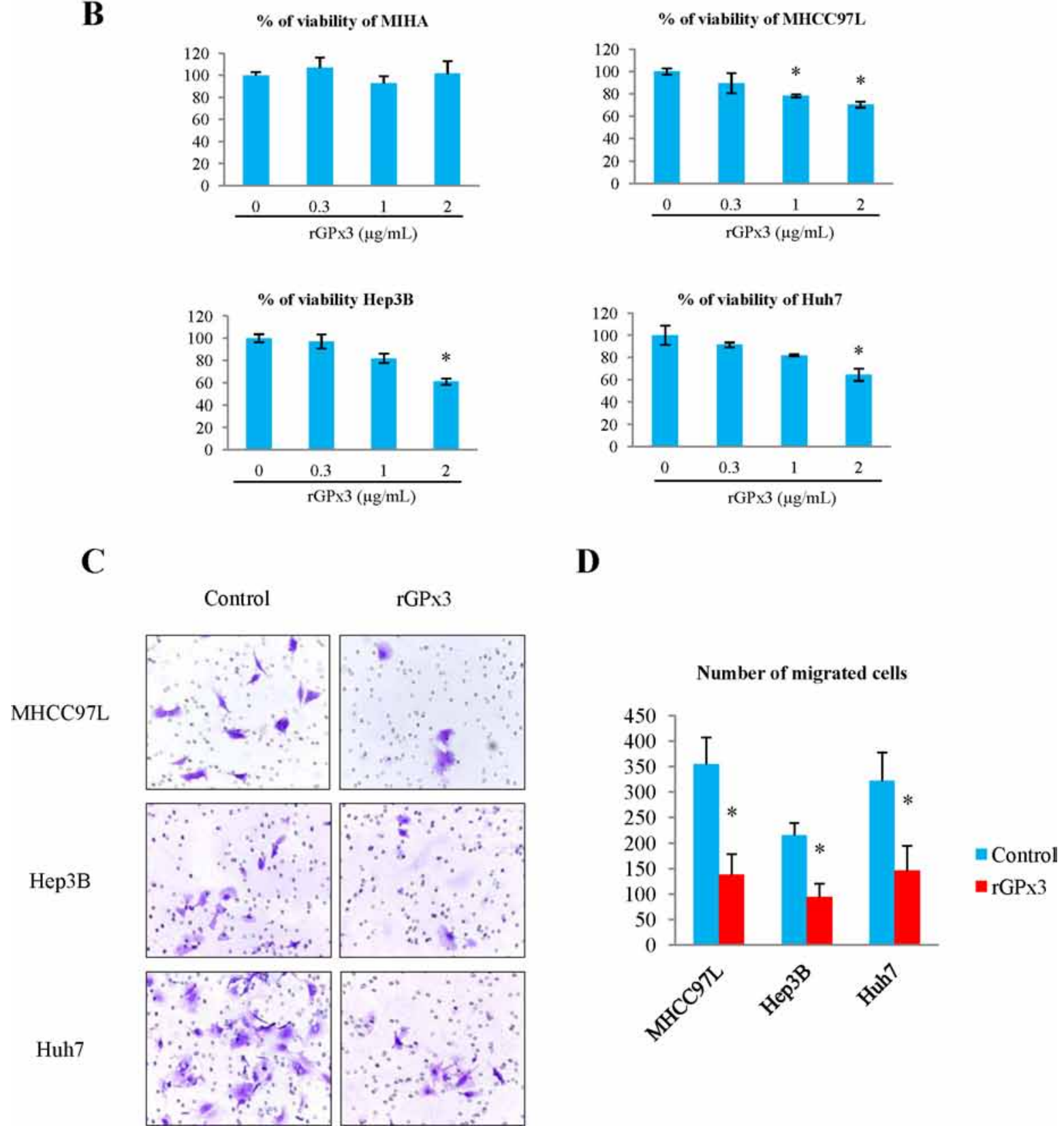

Figure 2: Effects of rGPx3 on HCC cells. (A) GPx3 mRNA in different cell lines, ${ }^{*} P<0.05$ vs MIHA and $\mathrm{LO}_{2}$; ${ }^{\sharp} P<0.05$ vs Hep3B and Huh7. (B) The effect of rGPx3 on proliferation of different cells, ${ }^{*} P<0.05 v s 0 \mu \mathrm{g} / \mathrm{mL}$. (C and D): The effect of rGPx3 on invasiveness of HCC cells. 
A

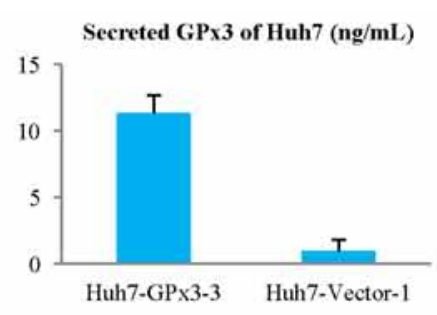

B

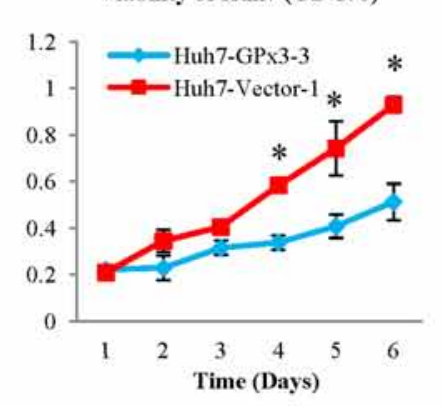

C
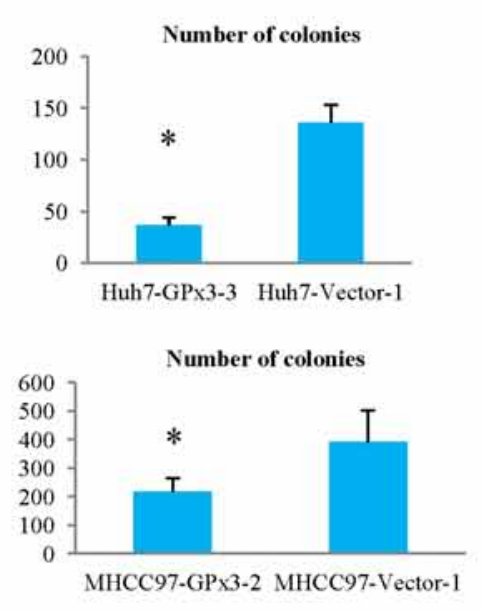

D
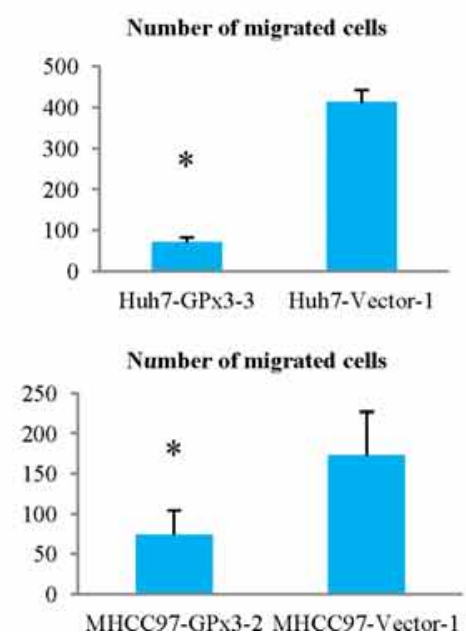

Secreted GPx3 of MHCC $97 \mathrm{~L}(\mathrm{ng} / \mathrm{mL})$

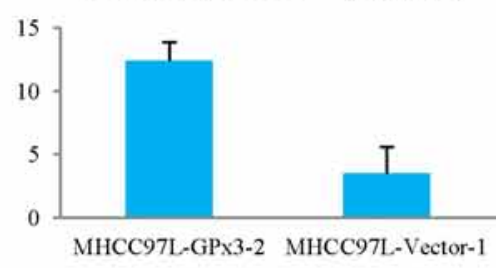

Viability of MHCC97L (OD 570)
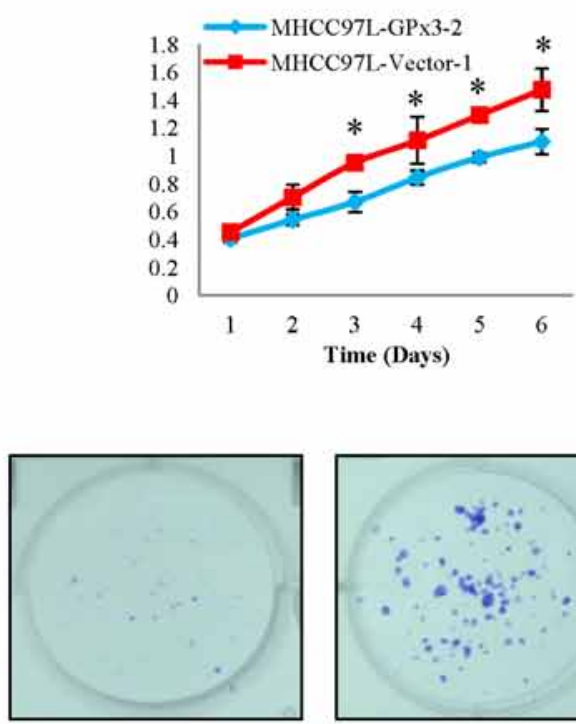

Huh7-GPx3-3

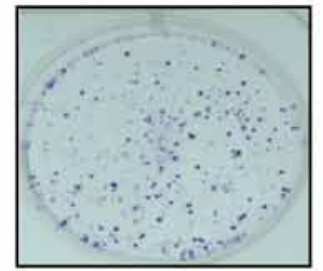

MHCC97L-GPx3-2

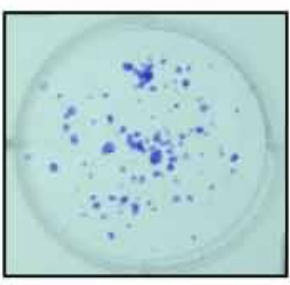

Huh7-Vector-1

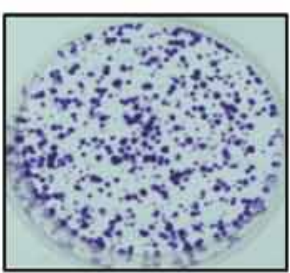

MHCC97L-Vector-1

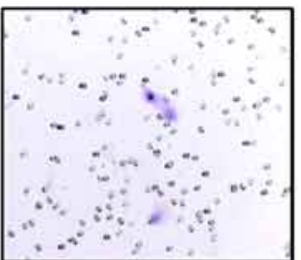

Huh7-GPx3-3

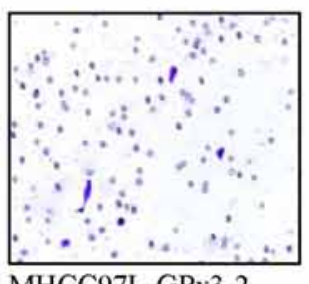

MHCC97L-GPx3-2

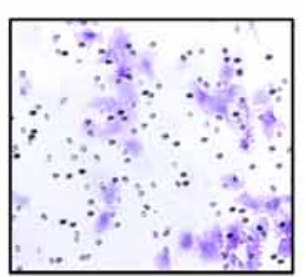

Huh7-Vector-1

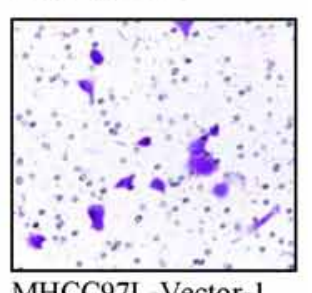

Figure 3: Effects of over-expression of GPx3 on HCC cells. (A) Secreted GPx3 in culture medium. (B) MTT assay, ${ }^{*} P<0.05$. (C) Colony formation assay, ${ }^{*} P<0.05$. (D) Matrigel invasion assay, ${ }^{*} P<0.05$. 
A

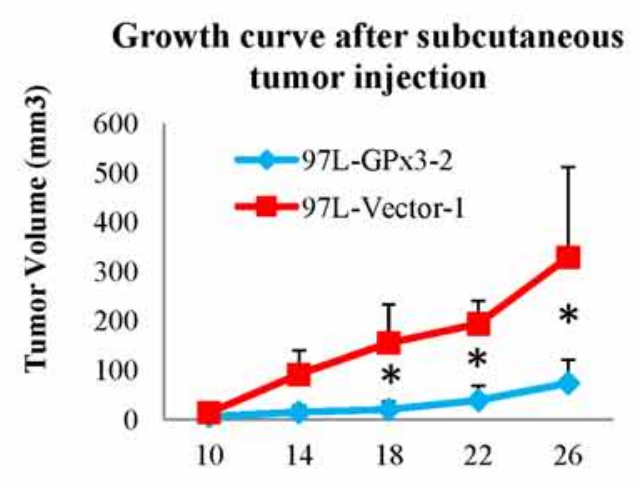

\section{Tumor weight after Subcutaneous injection}

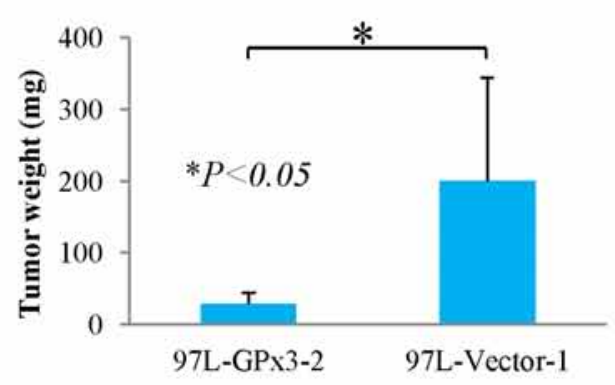

B

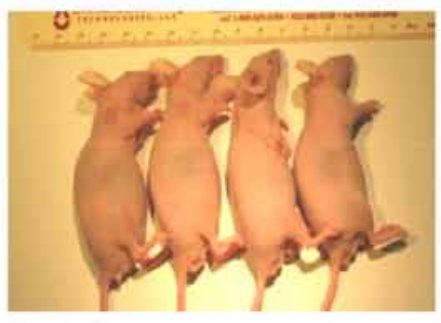

97L-GPX3-2

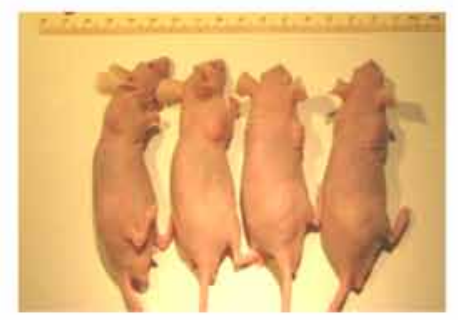

97L-Vector-1

C

Tumor volume $\left(\mathrm{mm}^{3}\right)$
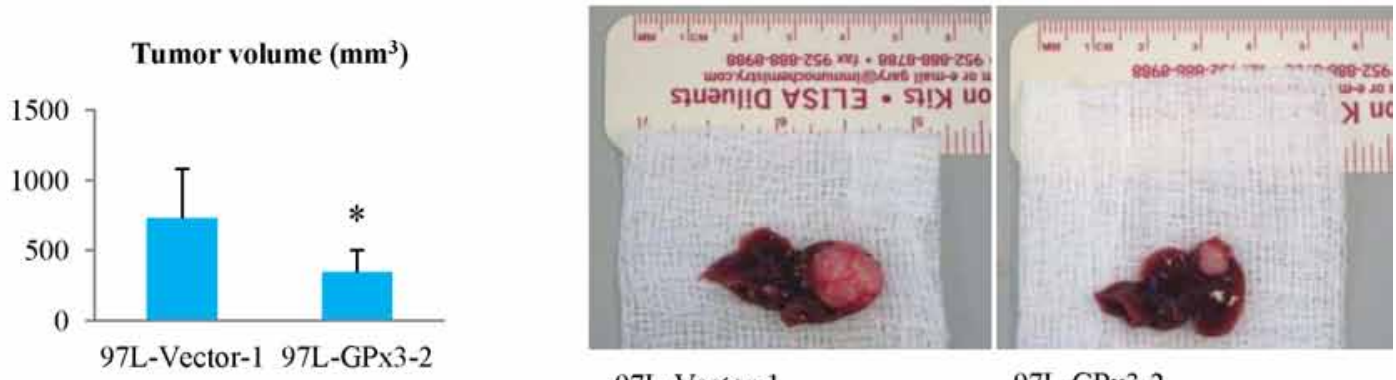

97L-Vector-1

97L-GPx3-2

D

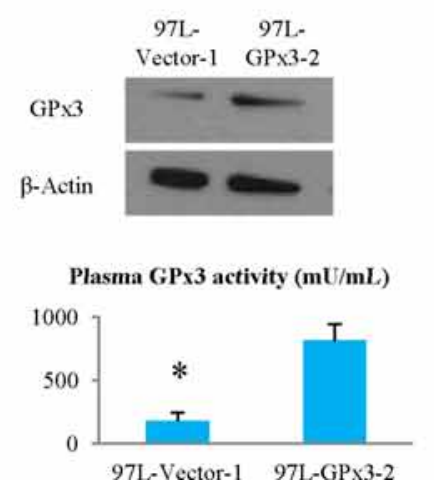

E

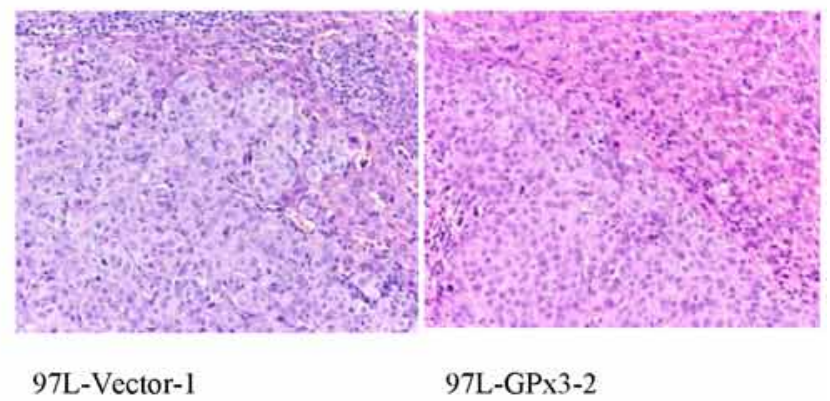

Figure 4: Effects of over-expression of GPx3 on tumor growth in nude mice ectopic and orthotopic liver cancer model. (A and B) Over-expression of GPx3 significantly inhibited subcutaneous tumor growth, $* P<0.05$. (C) Over-expression of GPx3 significantly inhibited orthotopic tumor growth, $* P<0.05$. (D) Over-expression of GPx3 could be maintained 5 weeks after implantation. (E) Representative images of HE staining $(400 \times)$. 
A

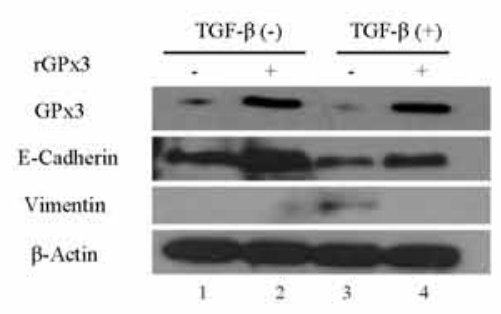

C

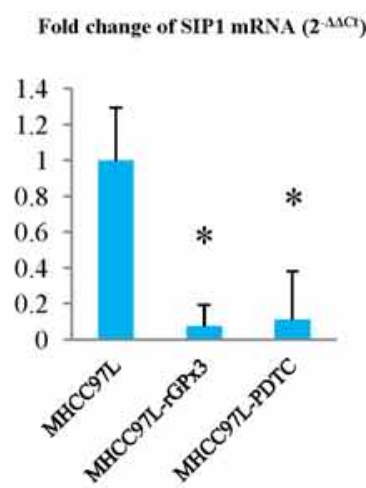

B

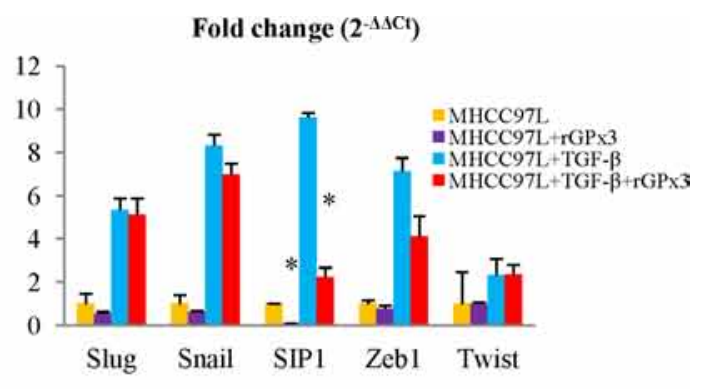

Dapi

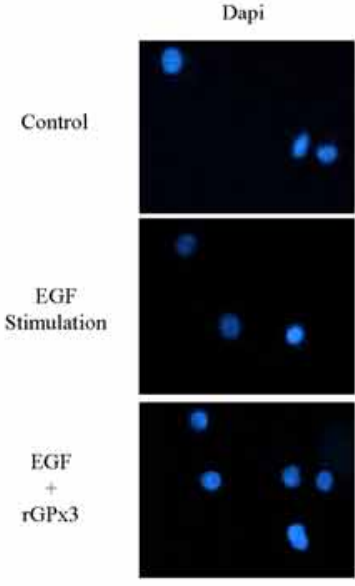

NF- $\mathrm{kB}-\mathrm{p} 65$
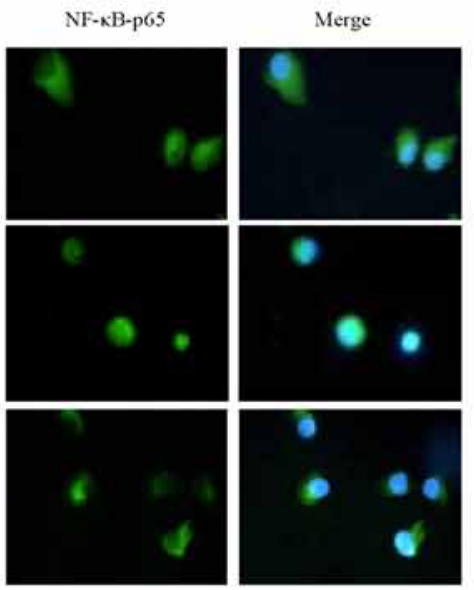

D

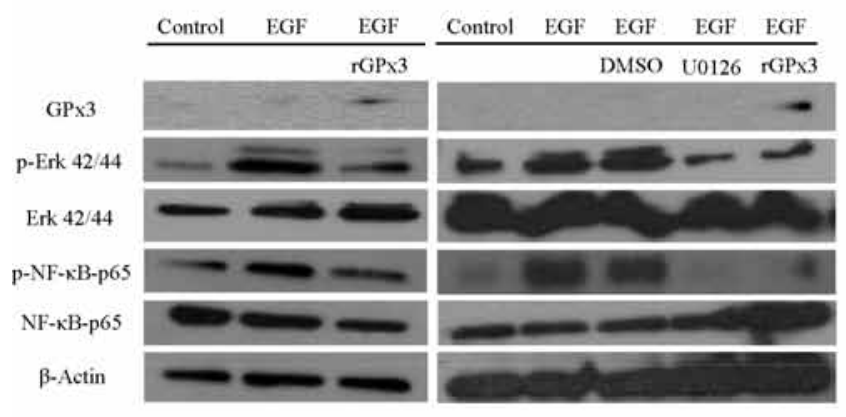

E Orhotopic xenograft tumor model

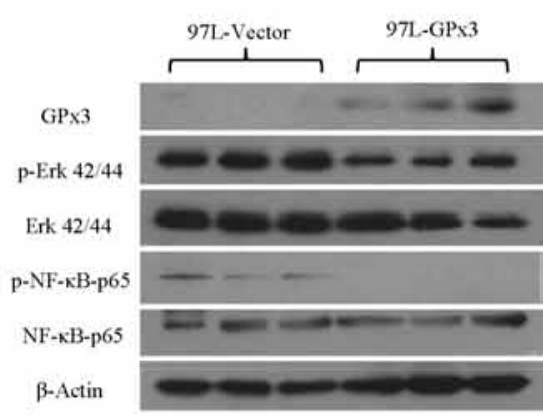

F

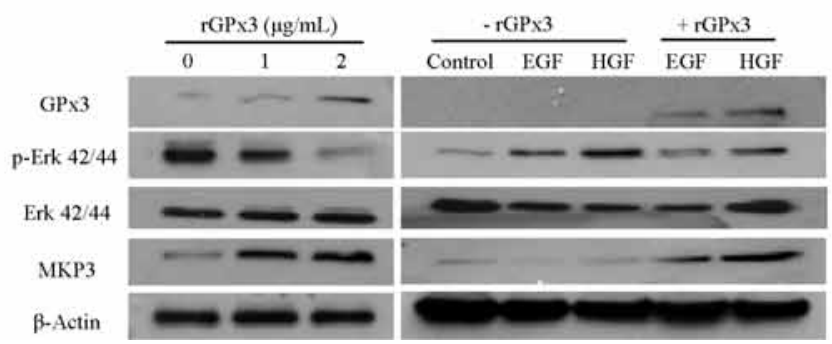

G

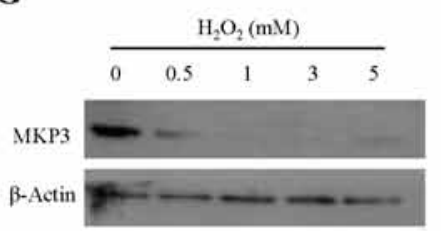

Figure 5: Potential mechanism for tumor suppressive activity of GPx3. (A) GPx3 inhibited EMT in MHCC97L. (B) GPx3 inhibited EMT through suppression of SIP1. (C) GPx3 suppressed expression of SIP1 through inhibition of NFKB nuclear translocation (right panel). SIP1 expression could be regulated by NFKB pathway evidenced by effect of specific NFKB inhibitor (PDTC, left panel). (D) GPx3 inhibited activation of NFKB through deactivation of Erk (left panel). Activation of NFkB could be regulated by Erk pathway evidenced by effect of specific Erk inhibitor (U0126, right panel). (E) Deactivation of NFkB and Erk by GPx3 was confirmed in orthotopic tumor model. (F) GPx3 inhibited Erk activation in a dose dependent manner and attenuated EGF- and HGF- induced Erk activation through restoration of MKP3 expression. (G) Expression of MKP3 in MHCC97L was negatively regulated by $\mathrm{H}_{2} \mathrm{O}_{2}$. 
Erk signaling pathway, such as Raf and MEK, were not changed upon GPx3 treatment (Fig. S2A). It implied that deactivation of Erk by GPx3 may not be mediated through Raf-MEK pathway. It was reported that the negative feedback of Erk activation was regulated by MKP3 [22], which was Erk phosphatase and widely expressed in liver tissue. In our case, MKP3 was significantly up-regulated upon rGPx3 treatment in a dose dependent manner (Fig. 5F, left panel). Furthermore, GPx3 could attenuate EGF (Epidermal Growth Factor) and HGF (Hepatocyte Growth Factor) induced Erk activation through the restoration of MKP3 expression (Fig. 5F, right panel). Thus, the inhibitory effect of GPx3 on Erk activation might be mediated through up-regulation of MKP3, which could maintain the negative feedback loop of Erk activation (Fig. S3). Moreover, our study showed that expression of MKP3 could be negatively regulated by $\mathrm{H}_{2} \mathrm{O}_{2}$ level (Fig. 5G). Thus, the restoration of MKP3 expression by GPx3 might be mediated through elimination of $\mathrm{H}_{2} \mathrm{O}_{2}$ due to the detoxification of GPx3.

\section{Engineered hiPSC-MSCs delivering GPx3 was established}

In order to explore the therapeutic value of GPx3 using hiPSC-MSCs as a delivery vehicle in $\mathrm{HCC}$, we established the engineered hiPSC-MSCs delivering GPx3. Full length of human GPx3 gene was transduced into the hiPSC-MSC cell line [23]. The transduction efficiency was confirmed to be nearly $100 \%$ (Fig. S4A). The protein level of intracellular GPx3 and secreted GPx3 in culture medium were both confirmed to be significantly elevated after transduction (Fig. S4B). The stem cell property of hiPSC-MSCs was still maintained after transduction as evidenced by positive and negative markers detected using flow cytometry (Fig. S5).

\section{Engineered hiPSC-MSCs delivering GPx3 significantly suppressed tumor growth in vitro}

The significant inhibitory effect of hiPSC-MSCGPx3 on the proliferation of MHCC97L cells was observed when the cell number ratio reached $2: 1$ or $1: 1$ (MHCC97L:hiPSC-MSC-GPx3) in MTT assay (Fig. 6A). In order to avoid the influence of proliferation of hiPSCMSCs in detection, hiPSC-MSC-GPx3 was co-cultured with MHCC97L cells labeled with luciferase (Fig. 6B). The bioluminescence of MHCC97L was significantly lower in the hiPSC-MSC-GPx3 group. It implied that hiPSC-MSC-GPx3 could significantly suppress the proliferation of MHCC97L cells (Fig. 6C).

\section{Engineered hiPSC-MSCs delivering GPx3 significantly suppressed tumor growth in vivo}

The subcutaneous tumor growth curve was significantly lower in the hiPSC-MSC-GPx3 treatment group (Fig. 7A). In the orthotopic model, the tumor volume was significantly lower in the hiPSC-MSC-GPx3 treatment group when nude mice were sacrificed (Fig. 7B). The kinetic images of tumor growth also showed that hiPSC-MSC-GPx3 treatment significantly suppressed orthotopic tumor growth in vivo (Fig. 7C). According to immunoflorescence and IHC staining, human hiPSCMSCs could be traced within tumor tissues (Fig. 7D, middle panel). Moreover, GPx3 expression could be detected at the same area at which hiPSC-MSC-GPx3 cells were located (Fig. 7D, lower panel). It implied that GPx3 could be successfully delivered by hiPSC-MSCs into tumor tissues.

\section{DISCUSSION}

We demonstrated that the lower plasma GPx3 indicated tumor recurrence and shorter disease-freesurvival period of HCC patients after liver resection. The down-regulation of GPx3 within tumor tissue also significantly correlated with advanced tumor stage and appearance of venous infiltration in HCC patients. These findings implied that GPx3 may possess prognostic value to predict $\mathrm{HCC}$ progression and recurrence. Although numerous biomarkers have been studied in past decades, the serological detection of HCC recurrence mainly relies on the traditional marker AFP [4, 24]. However, the positive predictive value (PPV) of AFP is not satisfied [25]. Furthermore, as the secreted proteins originated from tumors, AFP does not possess therapeutic value for HCC patients. So far, there is no promising biomarker possessing both prognostic and therapeutic value for HCC patients. In addition to indicating the clinical significance of GPx3, we also illustrated that over-expression of GPx3 in HCC cells significantly suppressed tumor proliferation and invasiveness in vitro and in vivo. More importantly, we demonstrated, for the first time that the tumor suppressive activity of GPx3 delivered by hiPSC-MSCs indicated the therapeutic potential of hiPSC-MSC-GPx3 for HCC patients. Based on the advantages that patient specific hiPSC-MSCs could be prepared as an "off-theshelf" source with a higher capacity of self-renewal and engraftment [23], the clinical application of hiPSCMSC-GPx3 may be a practical choice to prevent tumor recurrence and improve prognosis of $\mathrm{HCC}$ patients after liver surgery.

Epigenetic hypermethylation and genome deletion are reported as two reasons for the down-regulation of GPx3 during cancer development [7, 8, 26, 27], but the mechanism of down-regulation of GPx3 contributing to tumor progression remains to be investigated. GPx3 has been reported to commit its tumor suppressive activity through inhibition of c-Met expression in prostate cancer [28]. However, we did not find any difference of c-Met expression in $\mathrm{HCC}$ cell lines with forced expression of GPx3 (Fig. S2B). It indicated that tumor suppressive activity of GPx3 through down-regulation of c-Met may be 
A
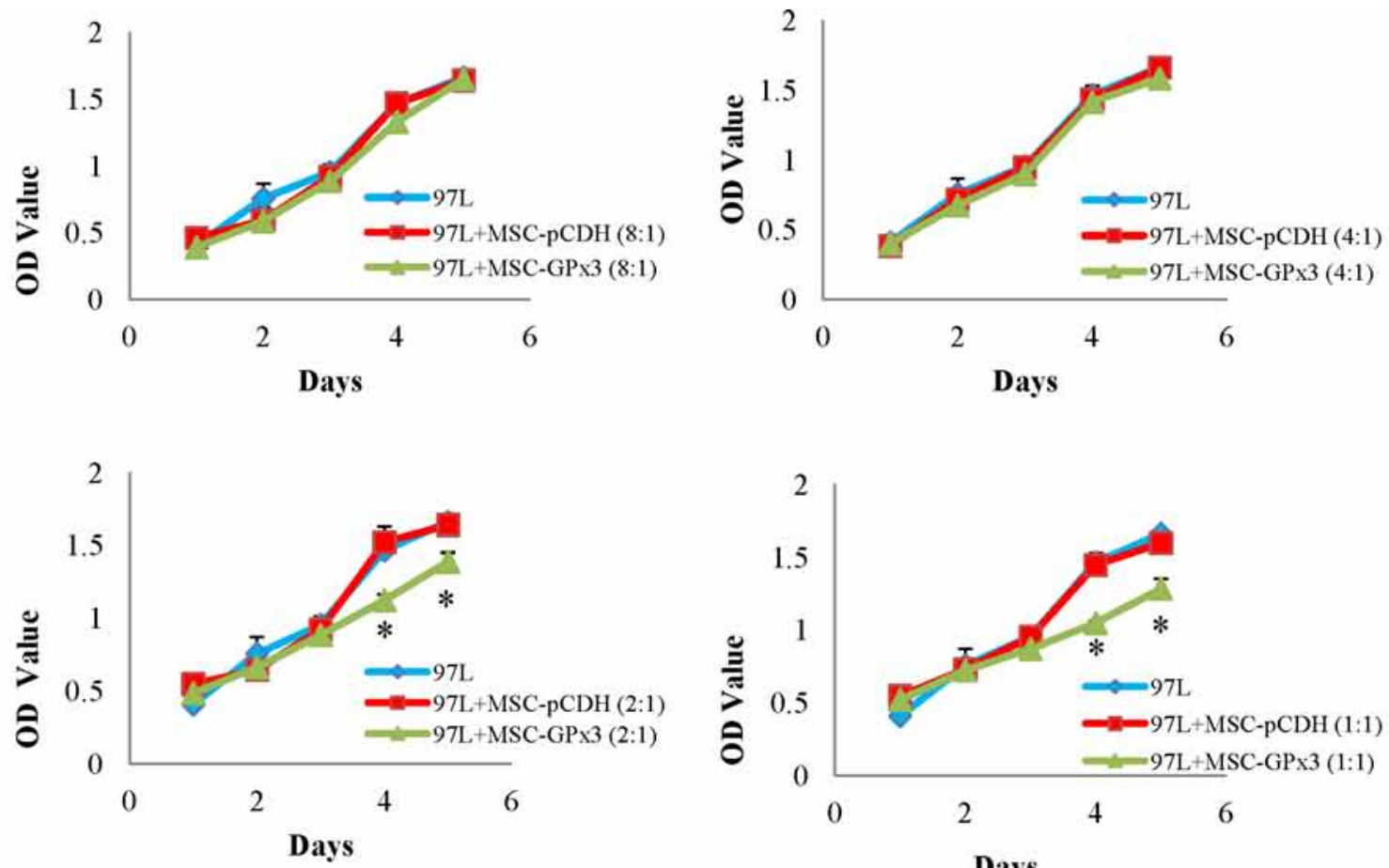

B

MHCC97L

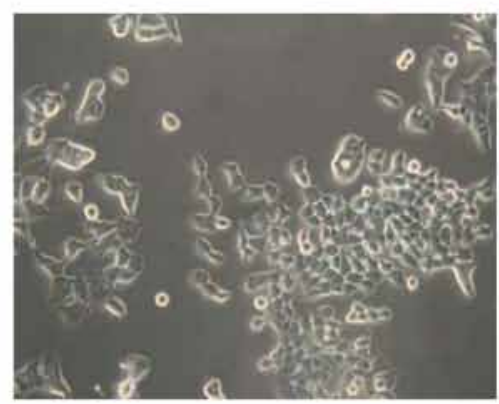

MHCC97L + MSC-pCDH

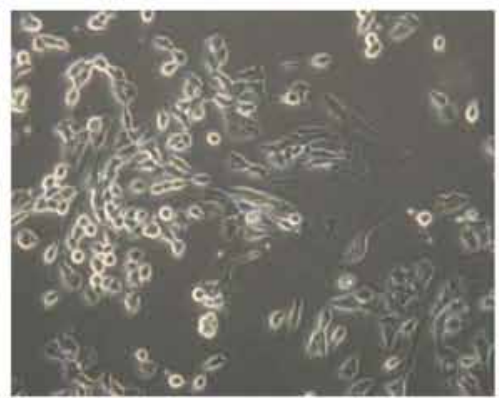

MHCC97L + MSC-GPx3

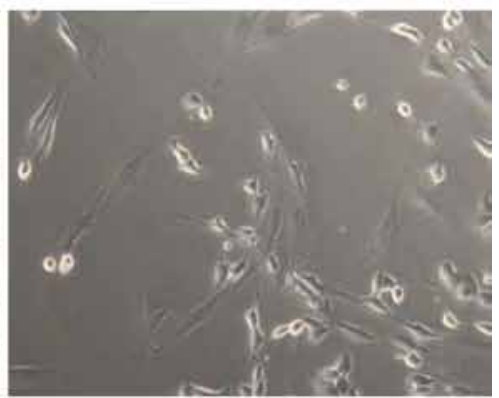

C
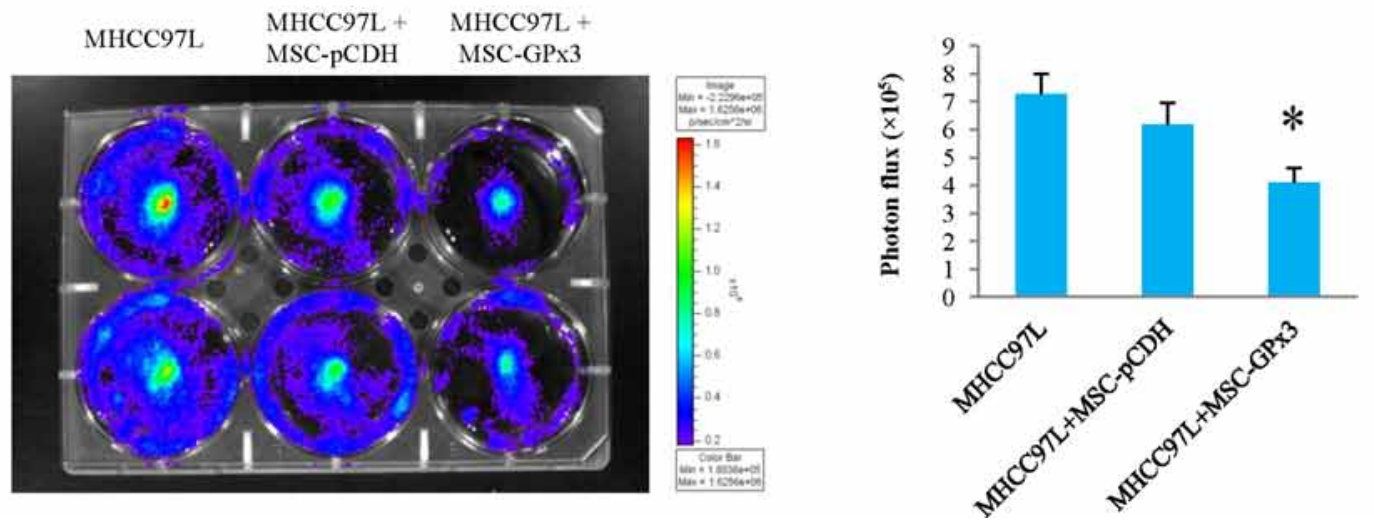

Figure 6: Tumor suppressive activity of hiPSC-MSC-GPx3 in vitro. (A) hiPSC-MSC-GPx3 significantly inhibited proliferation of MHCC97L in MTT assay, ${ }^{*} P<0.05$. (B and $\mathbf{C}$ ) hiPSC-MSC-GPx3 significantly inhibited proliferation of MHCC97L shown by bioluminescence, ${ }^{*} P<0.05$. 
A
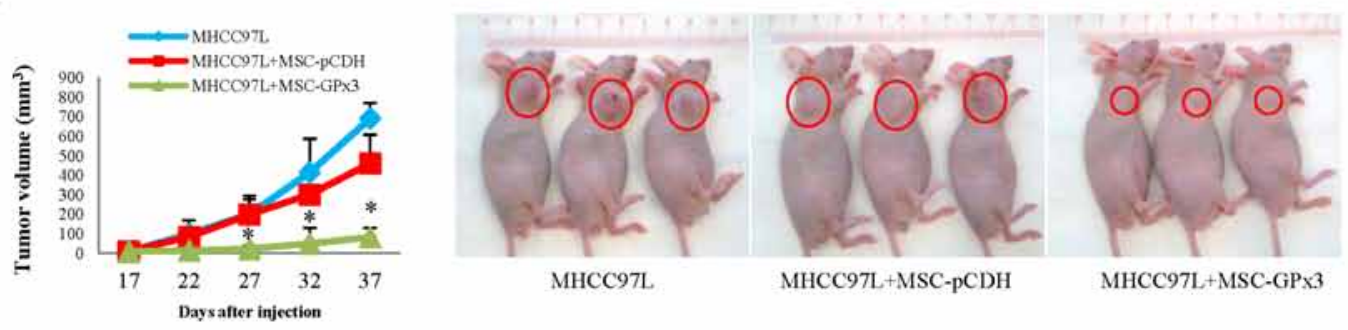

B

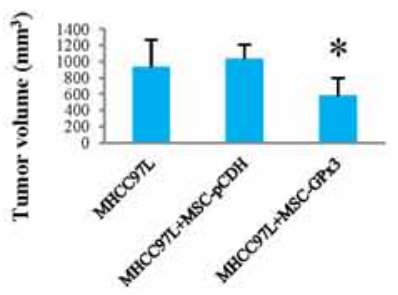

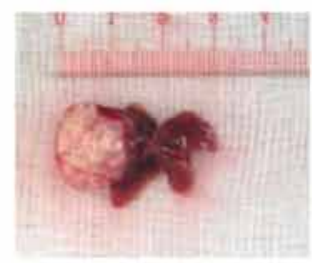

MHCC97L

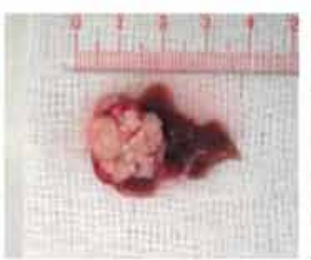

MHCC97L+MSC-pCDH

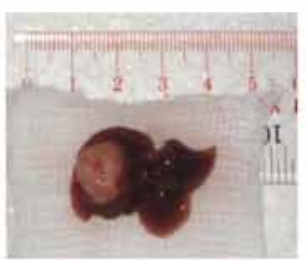

MHCC97L+MSC-GPx3

C MHCC97L MHCC97L+MSC-pCDH MHCC97L+MSC.

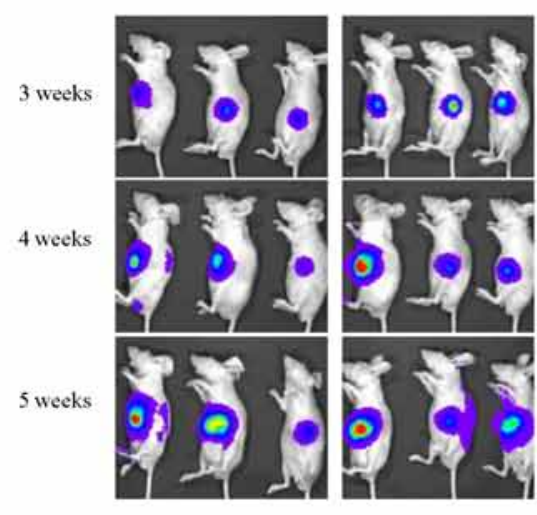

$\mathrm{GPx} 3$
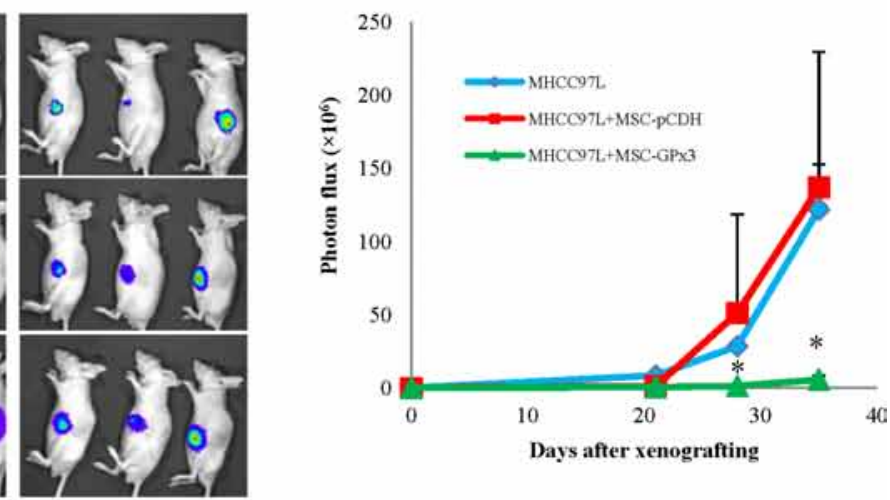

D

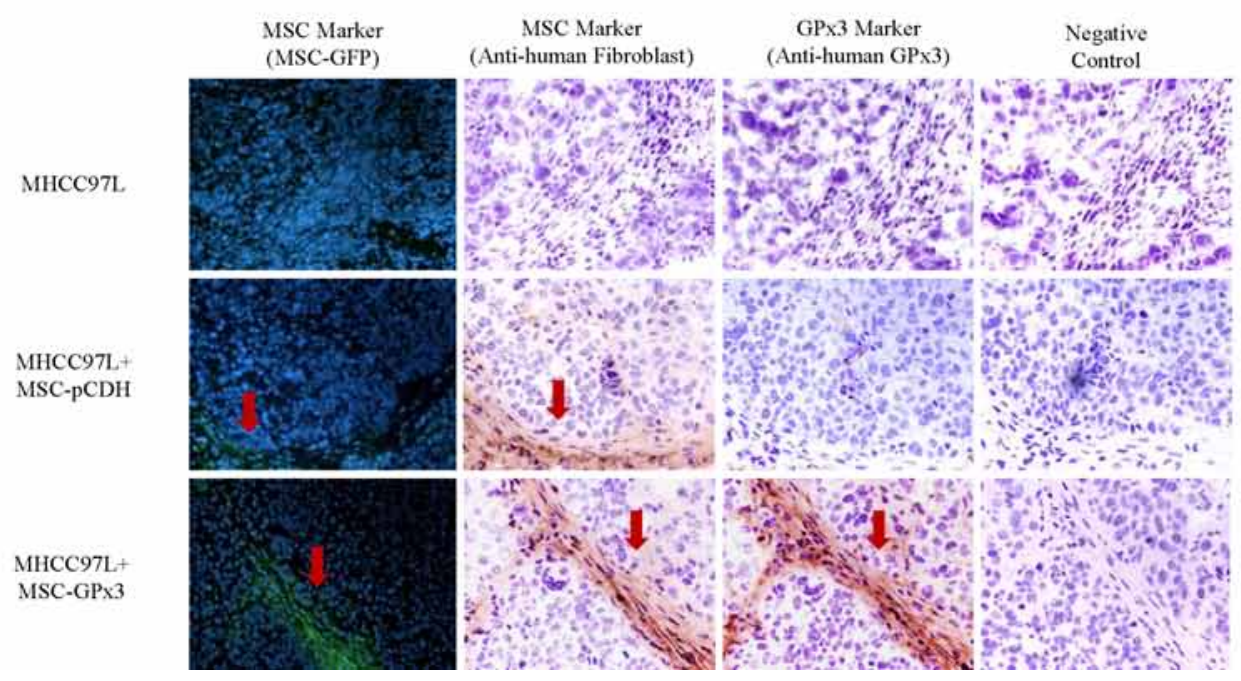

Figure 7: Tumor suppressive activity of hiPSC-MSC-GPx3 in vivo. (A) Subcutaneous tumor growth curve was significantly lower in hiPSC-MSC-GPx3 group. (B) Orthotopic tumor volume was significantly lower in hiPSC-MSC-GPx3 group. (C) Kinetic images of tumor growth showed tumor suppressive activity of hiPSC-MSC-GPx $3,{ }^{*} P<0.05$. (D) Successful delivery of GPx3 by hiPSCMSCs in tumor tissues. Pictures in each group showed the same area of tissue sections $(400 \times)$. 
cell-type-specific. Moreover, several reports demonstrated that the tumor suppressive function of GPx3 was mediated through induction of apoptosis in prostate and colon cancer $[29,30]$. However, in our study, no significant effect of GPx3 on apoptosis of HCC cells was observed (Fig. S1C). Consistently, we did not find any change in cell survival pathway, such as AKT pathway, after over-expression of GPx3 (Fig. S2A). It implied that other underlying mechanism might be existed for tumor suppressive activity of GPx3 in liver cancer. This is the first study to show that rGPx3 suppressed invasiveness of HCC cells by inhibition of EMT through Erk-NFאB-SIP1 signaling pathway. It has been reported that activation of $N F \kappa B$ could be determined by the Erk pathway [31]. It was consistent with our results. In addition, the regulatory effect of NFאB on SIP1 expression is also supported by Julien, who demonstrated that activation of NFאB promotes SIP1 expression which further suppresses E-cadherin expression [32]. We identified that only inhibition of SIP1, among five E-cadherin transcriptional repressors, was responsible for restoration of E-cadherin by rGPx3. So far, there is no promising SIP1 inhibitor for cancer therapy except for epigenetic silencing [33], in which the negative side effects may be inevitable. Besides that, the application of inhibitors of the NFKB pathway for cancer therapy is still at an early stage because of several severe side effects [34]. The hiPSC-MSC-GPx3 treatment with property of tumor tropism may be prospective for clinical utilization of cancer target therapy in HCC patients.

In addition to anti-invasiveness, significantly inhibitory effect of GPx3 or hiPSC-MSC-GPx3 on proliferation of HCC cells was also observed in vitro and in vivo. We found that GPx3 could maintain negative feedback of Erk activation by up-regulation of MKP3, which further deactivated the NFאB pathway. The inhibitory effect of GPx3 on Erk-NFкB activation might be able to explain the suppressive effect of GPx3 on both proliferation and invasiveness of HCC cells. This was confirmed in our animal model (Fig. 5E). Further research is required to understand whether there are other potential mechanisms involved in the tumor suppressive activity of GPx3.

Engineered MSC with an anti-tumor agent was reported as a novel strategy for cancer therapy with the advantage of fewer systemic side effects [35, 36]. However, the self-renewal capacity of bone-marrowderived-MSCs (BM-MSCs) was significantly deteriorated with aging [37]. The hiPSC-MSCs were discovered to possess a higher capacity of self-renewal with telomerase activity 10-fold higher than BM-MSCs [23]. Thus, it was of our great interest to explore the therapeutic value of GPx3 using hiPSC-MSCs as a delivery vehicle for HCC. The co-localization of hiPSC-MSCs and GPx3 expressions detected within tumor tissues highly implied that GPx3 can be successfully delivered by hiPSC-MSCs into the tumor site. This finding might provide a new delivery strategy for GPx3 in liver cancer target therapy.
We suggested that the lower circulating GPx3 possessed prognostic value for HCC patients. We not only investigated the clinical significance, but also further demonstrated the tumor suppressive role of GPx3 in HCC in vitro and in vivo. Moreover, we discovered the potential mechanism of GPx3 that suppressed invasiveness of tumor by inhibition of EMT through the Erk-NFאB-SIP1 signaling pathway. Most importantly, we further demonstrated therapeutic value of GPx3 using hiPSC-MSCs as a delivery vehicle in liver cancer models. Further investigation is required to explore the therapeutic effect of hiPSC-MSCGPx3 combined with other anti-tumor agents.

\section{MATERIALS AND METHODS}

\section{Study design}

The flow diagram of study design is shown in Fig. S6. In clinical association study, the correlation of GPx3 expression with clinicopathological features and survival outcome were investigated in $113 \mathrm{HCC}$ patients, who had undergone hepatectomy. In functional study, the effects of GPx3 on HCC cells were examined by administration of rGPx3 and forced expression of GPx3 in HCC cells in vitro, and the in vivo role of GPx3 was explored in ectopic and orthotopic xenograft liver cancer models. In mechanism study, effects of GPx3 on the EMT process and the activation of Erk-NFкB-SIP1 pathway were further explored. In translational study, the therapeutic value of GPx3 in HCC was explored using hiPSC-MSCs as a delivery vehicle in vitro and in vivo.

\section{Clinical association study}

\section{Clinical specimens}

The study was approved by the Institutional Review Board of the University of Hong Kong / Hospital Authority Hong Kong West Cluster. 113 HCC patients who had undergone curative partial hepatectomy between November 1999 and May 2009 were recruited with informed consent from the Department of Surgery, Queen Mary Hospital, The University of Hong Kong. All the patients were diagnosed with primary HCC and the patients with severe systemic disorder or combined with other tumors were excluded from the study. The median of follow up time was 6 years ( 2 months -11 years). The median age of the patients was 55 (22-81) years old. Eighty one percent of patients were male. Eighty eight percent of patients were HBsAg positive. One hundred and thirteen pairs of fresh tumor tissue and adjacent nontumor tissue samples were collected from HCC patients and 10 normal liver tissue samples were collected from donors during operation. One hundred and seven plasma samples were collected within a week pre-operation. 
Real time quantitative reverse transcription polymerize chain reaction (qRT-RCR), Immunohistochemistry (IHC) and Western-Blot

The mRNA level of GPx3 was determined by qRT-PCR. The protein level of GPx3 was detected by IHC and Western-blot as previously described [38]. GPx3 primary anti-body (Abcam) was used in immunostaining. The sequences of primers used were recorded (Table S2).

\section{Enzyme-linked immunosorbent assay (ELISA)}

The plasma samples were diluted 800 times and the medium for cell culture was without any dilution before detection. The concentration of GPx3 was tested using ELISA kit according to instruction manual (AdipoGen Inc, Incheon, Korea).

\section{In Vitro functional study}

\section{Cell culture, transfection and stable cell lines}

Human liver cancer cell lines (HepG2, Hep3B and Huh7) and human immortal liver cell lines (MIHA and $\mathrm{LO}_{2}$ ) were purchased from the American Type Culture Collection (Manassas, VA, USA). The metastatic human liver cancer cell line MHCC97L was obtained from the Liver Cancer institute and Zhongshan Hospital of Fudan University, Shanghai, the People's Republic of China [39]. All the cell lines were cultured as previously described [40]. The pcDNA 3.1 (+) vector was purchased from Invitrogen (Carlsbad, CA). MHCC97L and Huh7 cells were transfected with recombinant plasmid using lipofectamine 2000 Reagent (Invitrogen, Carlsbad, CA) and cultured for two weeks under G418 selection. Stable clones were maintained in $0.05 \mathrm{mg} / \mathrm{mL} \mathrm{G} 418$ for Huh 7 cells and $0.5 \mathrm{mg} / \mathrm{mL}$ for MHCC97L cells, respectively.

\section{3-(4,5-dimethylthiazol-2-yl)-2,5-diphenyltetrazolium bromide (MTT) assay and Colony formation assay}

In order to explore the proliferation rate of $\mathrm{HCC}$ cells, MTT and colony formation assay were performed as previously described [40].

\section{Matrigel invasion assay}

Around $5 \times 10^{4}$ cells were seeded into the upper chamber (BD Biosciences) in $0.5 \mathrm{ml}$ of serum-free DMEM. In the meantime, the lower chamber was filled up using DMEM with 10\% FBS as a chemoattractant. The cells were incubated at $37^{\circ} \mathrm{C}$ with $5 \% \quad \mathrm{CO}_{2}$ for $24 \mathrm{~h}$ for Huh7 and $48 \mathrm{~h}$ for $\mathrm{MHCC} 97 \mathrm{~L}$, respectively. After that, cells left on the upper surface of the chamber were removed gently using a cotton tip. Cells that had penetrated through the membrane of chamber were fixed by methanol at $-20^{\circ} \mathrm{C}$ for $20 \mathrm{~min}$, stained with $0.1 \%$ crystal violet for $1 \mathrm{~h}$ and finally counted under a light microscope. The experiment was performed in triplicate.

\section{In Vivo functional study}

\section{Nude mice ectopic tumorigenesis model}

MHCC97L cells $\left(1 \times 10^{6}\right.$ cells in 100 ul saline $)$ were injected subcutaneously into the right flank of the nude mice (6-8weeks, male) under anaesthesia with an intraperitoneal injection of pentobarbital. When the tumor developed, the size was measured every 4 days for 3 weeks. The volume of the tumor was calculated as follows: tumor volume $\left(\mathrm{mm}^{3}\right)=1 / 2 \times$ length $\times$ width $^{2}$. Tumor weight was measured when the mice were sacrificed at 4 weeks after the injection of tumor cells. Tumor tissues were harvested for further analysis. Six mice were recruited for each of the experimental group. The study had been licensed according to Animal (Control of Experiments) Ordinance Chapter 340 by the Department of Health, Hong Kong Special Administrative Region. (ref.: (11-632) in DH/HA\&P/8/2/3 Pt. 31).

\section{Nude mice orthotopic xenograft liver cancer model}

When the subcutaneous tumors grew and reached $6 \mathrm{~mm} \times 6 \mathrm{~mm}$ in size, the animals were sacrificed by an overdose intraperitoneal injection of pentobarbital. The tumor tissues were harvested and cut into $1-2 \mathrm{~mm}^{3}$ cubes. The tumor tissue cubes were then implanted into the left liver lobes of another group of mice under anaesthesia as described previously [41]. Five weeks after the tumor implantation, the animals were sacrificed for samples collection and further analysis. Eight mice were recruited in each group. The study had been licensed according to Animal (Control of Experiments) Ordinance Chapter 340 by the Department of Health, Hong Kong Special Administrative Region. (ref.: (11-632) in DH/HA\&P/8/2/3 Pt. 31).

\section{Mechanism study}

\section{EMT detection}

In order to explore the mechanism of anti-invasiveness of rGPx3, the role of rGPx3 in the EMT process was detected. EMT of MHCC97L was pre-induced by TGF- $\beta$ in vitro and then treated with rGPx3. The epithelial and mesenchymal markers were detected afterwards. Five E-cadherin transcriptional repressors, Slug, Snail, SIP1, Zeb1 and Twist, which were commonly involved in the EMT process, were detected to identify which one was responsible for the inhibitory effect of rGPx3 on EMT. Details were listed in supplementary material. 


\section{Regulation of NFKB signaling pathway}

In order to explore whether the suppressive effect of rGPx3 on SIP1 was through inhibition of the NFkB signaling pathway, the activation of $\mathrm{NF \kappa B}$ in MHCC $97 \mathrm{~L}$ was pre-induced by EGF and then treated with rGPx3. The nuclear translocation of NFKB was observed by immunoflorescence. To explore whether the downregulation of SIP1 could be directly regulated by the

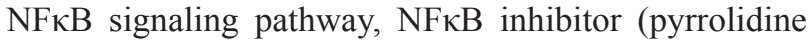
dithiocarbamate, PDTC, Sigma) was used. Details were listed in supplementary material.

\section{Regulation of Erk signaling pathway}

In order to investigate whether the inhibitory effect of rGPx3 on NFKB was through inhibition of Erk pathway, the activation of Erk was pre-induced in MHCC97L by EGF in vitro and then treated with $\mathrm{rGPx}$. To explore whether activation of $\mathrm{NF \kappa B}$ could be directly regulated by Erk signaling pathway, Erk inhibitor (U0126) was used. Details were listed in supplementary material.

\section{Regulation of MKP3 expression}

In order to explore whether inhibitory effect of rGPx3 on Erk activation was through regulation of MKP3, expression of MKP3 were detected in MHCC97L after rGPx3 administration. To explore whether MKP3 expression was regulated by ROS levels, different concentrations of $\mathrm{H}_{2} \mathrm{O}_{2}$ administration were applied. Details were listed in supplementary material.

\section{Translational study}

\section{Establishment of engineered hiPSC-MSCs delivering GPx3}

A full-length human GPx3 gene was transduced into expression plasmid pCDH-CMV-MCS-EF1-copGFP (System Biosciences, SBI). Virus particles were packaged in 293TN cells (System Biosciences, SBI). The hiPSCMSCs cell line was derived from our collaborator Dr. Lian [23]. Expression of GPx3 after transduction was confirmed by western-blot and Elisa. Stem cells' property was investigated after transduction using flow cytometry. Antibodies of positive markers CD44-PE, CD105-PE, CD90-PE and CD73-PE and negative markers CD34-PE and CD45-PE were purchased from Biosciences (BD).

\section{Investigation of tumor suppressive role of hiPSC-MSC-GPx3 in vitro}

The effect of hiPSC-MSC-GPx3 on the proliferation of MHCC97L cells was examined by MTT assay. MHCC97L was co-cultured with hiPSC-MSC-GPx3 at a different ratio for different time period. As
hiPSC-MSC-GPx 3 could hardly proliferate in the medium of MHCC 97L, the OD value of MTT assay mainly reflects the proliferation of MHCC $97 \mathrm{~L}$ cells. In order to distinguish two types of cells in co-culture system, MHCC97L $\left(1 \times 10^{4} /\right.$ well $)$ was labeled with luciferin and co-cultured with hiPSC-MSC-GPx3 $\left(5 \times 10^{3} /\right.$ well). Proliferation of MHCC 97L in co-culture system was shown as luciferin signal detected by Xenogen IVIS ${ }^{\circledR}$ in vivo imaging system.

\section{Investigation of tumor suppressive role of hiPSC- MSC-GPx3 in vivo}

The nude mice ectopic and orthotopic xenograft liver cancer models were established as described in section of in vivo functional study above. In the ectopic xenograft liver cancer model, MHCC97L $\left(2 \times 10^{6} / 100 \mu \mathrm{L}\right)$ was co-injected with hiPSC-MSC-GPx3 $\left(1 \times 10^{6} / 100 \mu \mathrm{L}\right)$ subcutaneously into the right flank of nude mice. Tumor size was measured every 5 days for 3 weeks. In orthotopic xenograft liver cancer model, hiPSC-MSCGPx3 $\left(1 \times 10^{6} / 100 \mu \mathrm{L}\right)$ was injected directly into the spleen after implantation of a tumor nodule on the surface of liver. Kinetic images of tumor growth in vivo were captured by Xenogen IVIS ${ }^{\circledR}$ in vivo imaging system. Migrated hiPSC-MSCs in tumor tissues were detected by immuno-florescence (GFP) and IHC staining with antihuman fibroblast anti-body DIA100 (Dianova, Germany). Expression of GPx3 was detected by IHC staining with anti-human GPx3 anti-body (Abcam).

\section{Statistical analysis}

The Chi-square test was used to compare categorical data. The $\mathrm{T}$ test was adopted to compare continuous variables. For mRNA level of GPx3 within tissues, 2 -fold difference was selected as cut-off point by which the patients could be segregated most evenly. Other cutoff points had also been taken into consideration and investigated. They showed the similar clinical implication. For plasma GPx3, The Youden index [42] was used to determine the optimal cutoff point for the prediction of five year recurrence. The cutoff point with the maximized Youden index showed the most optimal sensitivity and specificity for prediction. Kaplan-Meier survival analysis was performed to compare the survival outcome of HCC patients. The significant difference between survival outcomes was detected by the log-rank test. The Cox proportional hazard regression model was used to identify predictors for overall survival. The variables were selected into the final equation in multivariable analysis according to forward stepwise selection procedure. $P<0.05$ was considered as statistically significant. Calculations were made using SPSS computer software version 16 (SPSS Inc, Chicago, IL, USA). 


\section{GRANT SUPPORT}

This study was supported by the Collaborative Research Funding (HKU3/CRF/11R) and General Research Funding (GRF/HKU775011M) of the Research Grant Council Hong Kong.

\section{ACKNOWLEDGEMENT}

Special appreciation would be given to Miss Jennie J.J. Liu and Miss Samantha Fong for their manuscript editing.

\section{Disclosures}

No competing interests.

\section{REFERENCES}

1. Fiaschi T, Chiarugi P. Oxidative stress, tumor microenvironment, and metabolic reprogramming: a diabolic liaison. International journal of cell biology. 2012; 2012:762825.

2. Gasche C, Chang CL, Rhees J, Goel A, Boland CR. Oxidative stress increases frameshift mutations in human colorectal cancer cells. Cancer Res. 2001; 61: 7444-7448.

3. Nguyen HL, Zucker S, Zarrabi K, Kadam P, Schmidt C, Cao J. Oxidative stress and prostate cancer progression are elicited by membrane-type 1 matrix metalloproteinase. Molecular cancer research: MCR. 2011; 9:1305-1318.

4. Pavlides S, Tsirigos A, Migneco G, Whitaker-Menezes D, Chiavarina B, Flomenberg N, Frank PG, Casimiro MC, Wang C, Pestell RG, Martinez-Outschoorn UE, Howell A, Sotgia F, Lisanti MP. The autophagic tumor stroma model of cancer: Role of oxidative stress and ketone production in fueling tumor cell metabolism. Cell cycle. 2010; 9: 3485-3505.

5. Li YG, Ji DF, Zhong S, Shi LG, Hu GY, Chen S. Saponins from Panax japonicus protect against alcoholinduced hepatic injury in mice by up-regulating the expression of GPX3, SOD1 and SOD3. Alcohol 2010; 45: 320-331.

6. Manzanares W, Biestro A, Galusso F, Torre MH, Manay N, Pittini G, Facchin G, Hardy G. Serum selenium and glutathione peroxidase-3 activity: biomarkers of systemic inflammation in the critically ill? Intensive Care Med. 2009; 35:882-889.

7. He Y, Wang Y, Li P, Zhu S, Wang J, Zhang S. Identification of GPX3 Epigenetically Silenced by CpG Methylation in Human Esophageal Squamous Cell Carcinoma. Dig Dis Sci. 2010.

8. Peng DF, Razvi M, Chen H, Washington K, Roessner A, Schneider-Stock R, El-Rifai W. DNA hypermethylation regulates the expression of members of the Mu-class glutathione S-transferases and glutathione peroxidases in Barrett's adenocarcinoma. Gut. 2009; 58:5-15.

9. Murawaki Y, Tsuchiya H, Kanbe T, Harada K, Yashima K, Nozaka K, Tanida O, Kohno M, Mukoyama T, Nishimuki E, Kojo H, Matsura T, Takahashi K, Osaki M, Ito $\mathrm{H}$, Yodoi J, et al. Aberrant expression of selenoproteins in the progression of colorectal cancer. Cancer Lett. 2008; 259:218-230.

10. Sreekanthreddy P, Srinivasan H, Kumar DM, Nijaguna MB, Sridevi S, Vrinda M, Arivazhagan A, Balasubramaniam A, Hegde AS, Chandramouli BA, Santosh V, Rao MR, Kondaiah P, Somasundaram K. Identification of potential serum biomarkers of glioblastoma: serum osteopontin levels correlate with poor prognosis. Cancer Epidemiol Biomarkers Prev. 2010; 19:1409-1422.

11. Parkin DM, Bray F, Ferlay J, Pisani P. Global cancer statistics, 2002. CA Cancer J Clin. 2005; 55:74-108.

12. Lo CM, Fan ST, Liu CL, Chan SC, Ng IO, Wong J. Living donor versus deceased donor liver transplantation for early irresectable hepatocellular carcinoma. Br J Surg. 2007; 94:78-86.

13. Ng KK, Lo CM, Chan SC, Chok KS, Cheung TT, Fan ST. Liver transplantation for hepatocellular carcinoma: the Hong Kong experience. J Hepatobiliary Pancreat Sci. 2010; 17:548-554.

14. Poon RT, Fan ST. Hepatectomy for hepatocellular carcinoma: patient selection and postoperative outcome. Liver Transpl. 2004; 10:S39-45.

15. Amram ML, Benamran DA, Roth AD. [Targeted therapies in digestive oncology]. Rev Med Suisse. 2011; 7: 1131-1132:1134-1136.

16. Baek KK, Kim JH, Uhm JE, Park SH, Lee J, Park JO, Park YS, Kang WK, Lim HY. Prognostic Factors in Patients with Advanced Hepatocellular Carcinoma Treated with Sorafenib: A Retrospective Comparison with Previously Known Prognostic Models. Oncology. 2011; 80:167-174.

17. Kim JY, Chung SM, Choi BO, Kay CS. Hepatocellular carcinoma with portal vein tumor thrombosis: Improved treatment outcomes with external beam radiation therapy. Hepatol Res. 2011;

18. Lee SJ, Lee J, Park SH, Park JO, Park YS, Kang WK, Yim DS, Lim HY. Phase 1 trial of S-1 in combination with sorafenib for patients with advanced hepatocellular carcinoma. Invest New Drugs. 2011;

19. Chua HL, Bhat-Nakshatri P, Clare SE, Morimiya A, Badve S, Nakshatri H. NF-kappaB represses E-cadherin expression and enhances epithelial to mesenchymal transition of mammary epithelial cells: potential involvement of ZEB-1 and ZEB-2. Oncogene. 2007; 26:711-724.

20. Jiang B, Xu S, Hou X, Pimentel DR, Brecher P, Cohen RA. Temporal control of NF-kappaB activation by ERK differentially regulates interleukin-1beta-induced gene expression. J Biol Chem. 2004; 279:1323-1329. 
21. Kim NH, Jeon S, Lee HJ, Lee AY. Impaired PI3K/Akt activation-mediated NF-kappaB inactivation under elevated TNF-alpha is more vulnerable to apoptosis in vitiliginous keratinocytes. J Invest Dermatol. 2007; 127:2612-2617.

22. Li C, Scott DA, Hatch E, Tian X, Mansour SL. Dusp6 (Mkp3) is a negative feedback regulator of FGF-stimulated ERK signaling during mouse development. Development. 2007; 134:167-176.

23. Lian Q, Zhang Y, Zhang J, Zhang HK, Wu X, Lam FF, Kang S, Xia JC, Lai WH, Au KW, Chow YY, Siu CW, Lee CN, Tse HF. Functional mesenchymal stem cells derived from human induced pluripotent stem cells attenuate limb ischemia in mice. Circulation. 2010; 121:1113-1123.

24. Koteish A, Thuluvath PJ. Screening for hepatocellular carcinoma. Journal of vascular and interventional radiology: JVIR. 2002; 13:S185-190.

25. Befeler AS, Di Bisceglie AM. Hepatocellular carcinoma: diagnosis and treatment. Gastroenterology. 2002; 122: 1609-1619.

26. Lee OJ, Schneider-Stock R, McChesney PA, Kuester D, Roessner A, Vieth M, Moskaluk CA, El-Rifai W. Hypermethylation and loss of expression of glutathione peroxidase-3 in Barrett's tumorigenesis. Neoplasia. 2005; $7: 854-861$.

27. Zhang X, Yang JJ, Kim YS, Kim KY, Ahn WS, Yang S. An 8-gene signature, including methylated and downregulated glutathione peroxidase 3 , of gastric cancer. Int J Oncol. 2010; 36:405-414.

28. Yu YP, Yu G, Tseng G, Cieply K, Nelson J, Defrances M, Zarnegar R, Michalopoulos G, Luo JH. Glutathione peroxidase 3, deleted or methylated in prostate cancer, suppresses prostate cancer growth and metastasis. Cancer Res. 2007; 67:8043-8050.

29. Wang $\mathrm{H}$, Luo $\mathrm{K}$, Tan LZ, Ren BG, Gu LQ, Michalopoulos G, Luo JH, Yu YP. p53-induced gene 3 mediates cell death induced by glutathione peroxidase 3 . J Biol Chem. 2012; 287:16890-16902.

30. Barrett C, Ning W, Chen X, Smith JJ, Washington MK, Hill K, Peek RM Jr, Coburn LA, Chaturvedi R, Wilson KT, Burk RF, Williams CS. Tumor suppressor function of the plasma glutathione peroxidase Gpx3 in colitis-associated carcinoma. Cancer Res. 2012;

31. He Y, Wang Y, Li P, Zhu S, Wang J, Zhang S. Identification of GPX3 epigenetically silenced by CpG methylation in human esophageal squamous cell carcinoma. Dig Dis Sci. 2011; 56:681-688.

32. Julien S, Puig I, Caretti E, Bonaventure J, Nelles L, van Roy F, Dargemont C, de Herreros AG, Bellacosa A,
Larue L. Activation of NF-kappaB by Akt upregulates Snail expression and induces epithelium mesenchyme transition. Oncogene. 2007; 26:7445-7456.

33. Li A, Omura N, Hong SM, Vincent A, Walter K, Griffith M, Borges M, Goggins M. Pancreatic cancers epigenetically silence SIP1 and hypomethylate and overexpress $\mathrm{miR}-200 \mathrm{a} / 200 \mathrm{~b}$ in association with elevated circulating miR-200a and miR-200b levels. Cancer Res. 2010; 70: 5226-5237.

34. Yamamoto Y, Gaynor RB. Therapeutic potential of inhibition of the NF-kappaB pathway in the treatment of inflammation and cancer. The Journal of clinical investigation. 2001; 107:135-142.

35. Studeny M, Marini FC, Champlin RE, Zompetta C, Fidler IJ, Andreeff M. Bone marrow-derived mesenchymal stem cells as vehicles for interferon-beta delivery into tumors. Cancer Res. 2002; 62:3603-3608.

36. Kucerova L, Altanerova V, Matuskova M, Tyciakova S, Altaner C. Adipose tissue-derived human mesenchymal stem cells mediated prodrug cancer gene therapy. Cancer Res. 2007; 67:6304-6313.

37. Reiser J, Zhang XY, Hemenway CS, Mondal D, Pradhan L, La Russa VF. Potential of mesenchymal stem cells in gene therapy approaches for inherited and acquired diseases. Expert Opin Biol Ther. 2005; 5:1571-1584.

38. Man K, Shih KC, Ng KT, Xiao JW, Guo DY, Sun CK, Lim ZX, Cheng Q, Liu Y, Fan ST, Lo CM. Molecular signature linked to acute phase injury and tumor invasiveness in small-for-size liver grafts. Ann Surg. 2010; 251:1154-1161.

39. Li Y, Tang ZY, Ye SL, Liu YK, Chen J, Xue Q, Gao DM, Bao WH. Establishment of cell clones with different metastatic potential from the metastatic hepatocellular carcinoma cell line MHCC97. World J Gastroenterol. 2001; 7:630-636.

40. Geng W, Ng KT, Sun CK, Yau WL, Liu XB, Cheng Q, Poon RT, Lo CM, Man K, Fan ST. The role of proline rich tyrosine kinase 2 (Pyk2) on cisplatin resistance in hepatocellular carcinoma. PLoS One. 2011; 6:e27362.

41. Man K, Ng KT, Xu A, Cheng Q, Lo CM, Xiao JW, Sun BS, Lim ZX, Cheung JS, Wu EX, Sun CK, Poon RT, Fan ST. Suppression of liver tumor growth and metastasis by adiponectin in nude mice through inhibition of tumor angiogenesis and downregulation of Rho kinase/IFNinducible protein 10/matrix metalloproteinase 9 signaling. Clin Cancer Res. 2010; 16:967-977.

42. Youden WJ. Index for rating diagnostic tests. Cancer. 1950; $3: 32-35$. 